\title{
Review Article \\ Endothelium and Its Alterations in Cardiovascular Diseases: Life Style Intervention
}

\author{
Gaia Favero, ${ }^{1}$ Corrado Paganelli, ${ }^{2}$ Barbara Buffoli, ${ }^{1}$ \\ Luigi Fabrizio Rodella, ${ }^{1}$ and Rita Rezzani ${ }^{1}$ \\ ${ }^{1}$ Section of Anatomy and Physiopathology, Department of Clinical and Experimental Sciences, University of Brescia, \\ Viale Europa 11, 25123 Brescia, Italy \\ ${ }^{2}$ Department of Medical and Surgical Specialties, Radiological Sciences and Public Health, University of Brescia, \\ Viale Europa 11, 25123 Brescia, Italy
}

Correspondence should be addressed to Rita Rezzani; rezzani@med.unibs.it

Received 15 November 2013; Accepted 11 January 2014; Published 26 February 2014

Academic Editor: Iveta Bernatova

Copyright (C) 2014 Gaia Favero et al. This is an open access article distributed under the Creative Commons Attribution License, which permits unrestricted use, distribution, and reproduction in any medium, provided the original work is properly cited.

\begin{abstract}
The endothelium, which forms the inner cellular lining of blood vessels and lymphatics, is a highly metabolically active organ that is involved in many physiopathological processes, including the control of vasomotor tone, barrier function, leukocyte adhesion, and trafficking and inflammation. In this review, we summarized and described the following: (i) endothelial cell function in physiological conditions and (ii) endothelial cell activation and dysfunction in the main cardiovascular diseases (such as atherosclerosis, and hypertension) and to diabetes, cigarette smoking, and aging physiological process. Finally, we presented the currently available evidence that supports the beneficial effects of physical activity and various dietary compounds on endothelial functions.
\end{abstract}

\section{Introduction}

The term endothelium was coined in the 1865 by the anatomist Wilhelm His, who differentiated the inner lining of body cavities from epithelium. Wilhelm His defined as endothelium the cell lining blood vessels, lymphatics, and mesothelial-lined cavities. This definition was later modified including only the inner cell stratum of blood vessels and lymphatics. Actually, the endothelium is considered a monocellular layer that separates all tissues from the circulating blood $[1,2]$. In the 1950s and 1960s, the use of electron microscopy provided detailed and innovative ultrastructural information, revealing in endothelial cells (ECs) the presence of characteristic organelles, such as plasmalemmal vesicles, successively defined caveolae, and Weibel-Palade bodies [3, 4], and showed that the ECs are characterized by structural and functional heterogeneity. In fact, the shape and organization of cells vary across the vascular tree. Blood vessel endothelium traverses each and every tissue, but each vascular bed has unique structural and functional properties and this reflected ECs heterogeneity [5].
ECs are absent in invertebrates, cephalochordates, and tunicates but are present in the three major groups of extant vertebrates: hagfish, lampreys, and jawed vertebrates. This observation underlines that the endothelium is shared by jawless and jawed vertebrates and that it was present in the ancestor of these animals. So, it is a tissue structure conserved during the evolution of vertebrate. Yano et al. [6], for the first time, observed an unequivocal existence of organ specific properties of the endothelium confirming the structural and functional EC heterogeneity.

Developmentally, endothelium arises from mesoderm via the differentiation of hemangioblasts and/or angioblasts. However, other cell lineages may transdifferentiate into ECs and ECs into other lineages [7]. Precursor of ECs is thought to arise from the ventral floor of the dorsal aorta within the aorta-gonad-mesonephros region. Splanchnopleuric mesoderm transforms into mesenchymal cells, which differentiate into hemangioblasts. The hemangioblasts, then, become preECs, which can further differentiate into either a committed haemopoietic cell line or in an EC [8]. 
This review will summarize and update the morphological and functional features of the endothelium and it will provide an overview of the major mechanisms participating in the alteration of endothelial functions at cardiovascular level in physiopathological states.

\section{An Anatomical Overview}

The anatomical structure of the endothelium is extremely simple and linear: a single layer of mesenchymal cells; despite the fact that the endothelium is an extremely complex tissue from the metabolic point of view. The EC surface in an adult human is composed approximately of 1 to $6 \times 10^{13}$ cells, weighs approximately $1 \mathrm{~kg}$, and covers a surface area of about 1 to $7 \mathrm{~m}^{2}[9,10]$. Moreover, the ECs are generally flat, but most of the thickness of the endothelium is determined by a dynamic structure lying on its luminal surface [1]. ECs, that are typically flat, could be also plump or cuboidal in high endothelial venules (HEV) $[11,12]$ and EC thickness varies from less than $0.1 \mu \mathrm{m}$ in capillaries and veins to $1 \mu \mathrm{m}$ in the aorta $[3,13]$.

Endothelium may be continuous or discontinuous: continuous endothelium, in turn, may be fenestrated or nonfenestrated. The fenestrae are transcellular pores of about $70 \mathrm{~nm}$ in diameter extending through the full thickness of the cell and possessing a thin 5 to $6 \mathrm{~nm}$ nonmembranous diaphragm across their opening. The density of fenestrae varies through vascular beds [3]. In particular, continuous endothelium is characterized by ECs tightly connected to one another and surrounded by a continuous basement membrane; the subset of the continuous endothelium, defined fenestrate endothelium, has ECs permeated with holes or fenestrae, whereas the discontinuous endothelium is characterized by the presence of fenestrae, frank gaps, and a poorly formed underlying basement membrane [3]. Nonfenestrated continuous endothelium is found in arteries, veins, and capillaries of the brain, skin, heart, and lung. Fenestrated continuous endothelium, however, is characteristic of zone of high filtration or of transendothelial transport, such as capillaries of exocrine and endocrine glands, gastric and intestinal mucosa, choroids plexus, glomeruli, and renal tubules. Discontinuous endothelium is found in certain sinusoidal vascular beds, prevalently at liver level (liver sinusoidal ECs possess larger fenestrations of 100 to $200 \mathrm{~nm}$ in diameter, but liver showed a spatial heterogeneity) $[3,14]$.

Arteries and veins are both lined by continuous nonfenestrated endothelium, but endothelial junctions in arteries are tighter compared with those in veins [15]. Capillaries are characterized by flat ECs surrounded by occasional pericytes and extracellular matrix [5]. Some postcapillary venules are characterised by endothelial-lined bicuspid microscopic valves [16]. These are identical in structure, location, and orientation to the cells of the larger veins valves, with the exception that their leaflets lack fibroblasts and myofibroblasts. The ECs of postcapillary venules are rich in vesiculovacuolar organelles, particularly in the thicker portions of the blood vessels $[5,17]$. Postcapillary venules are the preferred site for leukocyte and platelet trafficking, roll, and infiltration inducing endothelial
TABLE 1: High endothelial venules features with respect to normal venules, modified from Miyasaka and Tanaka (2004) [12].

\begin{tabular}{lcc}
\hline & Normal venules & High endothelial venules \\
\hline Endothelium & Flat & Tall and plump \\
Basal lamina & Thin & Thick \\
Perivascular sheath & Scant & Prominent \\
PECAM-1 & Moderate & Moderate \\
ICAM-1 & Very weak/absent & High \\
VE-cadherin & Moderate & Moderate \\
\hline
\end{tabular}

PECAM-1: platelet/endothelial cell adhesion molecule-1; ICAM-1: intercellular adhesion molecule-1; VE-cadherin: vascular endothelial-cadherin.

activation in states of inflammation $[18,19]$, hypercholesterolemia, haemorrhage shock, and ischemia/reperfusion [5, 20, 21].

An important example of EC structural heterogeneity is found in the HEVs of secondary lymphoid organs. Anatomically, HEVs are postcapillary venules, but they are distinct from ordinary venules in several aspects [12] and also ECs in HEVs demonstrate unique structural, molecular, and functional properties compared with other ECs in the body. Each HEV is composed of a prominent perivascular sheath, a thick basal lamina, and a layer of ECs that have a plump morphology [22] and express site-specific adhesion molecules and chemokines that promote the trafficking of lymphocytes between blood and lymph node [5, 12, 23]. Some adhesion molecules are common in both normal venules and HEVs, such as platelet/endothelial cell adhesion molecule-1 (PECAM-1) (also known as CD31), whereas certain molecules are expressed uniquely in HEVs. In particular, peripheral lymph nodes HEVs abundantly express highly glycosylated and sulphated forms of sialomucins, including glycosylation-dependent cell-adhesion molecule 1, CD34, podocalyxin, endoglycan, and endomucin. With respect to normal venules, numerous sialomucins are expressed also in HEVs, but in a glycosylated form. HEVs express also high levels of lymphoid chemokines, although normal venules generally do not, with some exceptions, such as intestine and skin venules [12]. At the ultrastructural level, HEVs are characterized by a prominent Golgi complex, abundant polyribosomes, and rough endoplasmic reticulum, indicating an intense biosynthetic activity not observed in flat ECs. They also contain many membrane-bound vesicular structures, multivesicular bodies, Weibel-Palade bodies, and a variety of dense bodies, indicating that HEVs are involved in secretion. Actually, very few HEV-specific markers are known: the best marker currently available is MECA-79 [11], which stains all HEVs within lymphoid tissues and does not react with postcapillary venules or large vessels in spleen, thymus, or nonlymphoid tissues [24]. HEVs showed also "spot-welded" junctions between high ECs $[11,25]$ that differ from the tight junctions characteristic of capillary and arterial endothelium, but are similar to the "nonoccluding" junctions found in normal postcapillary venules. These junctions probably facilitate the passage of lymphocytes between adjacent high ECs allowing massive lymphocyte emigration in HEVs [11] (Table 1). 
It is important to remember that also heart contains several endothelial compartments, including ECs of coronary arteries, capillaries, and endocardium. These subtypes of ECs differ in developmental origin, structure, and function. Endocardial ECs are larger than other types of ECs and possess many microvilli, which project into the heart cavity [5]. The relative abundance of gap junctions, such as connexins, expressed by endocardium but not by EC of myocardial capillary is due to the fact that the endocardium has more intercellular clefts, gap junctions, and few vesicles $[5,26]$. The ECs of coronary arteries are similar in structure and function to ECs of other arteries in the body; whereas capillaries in the heart possess a continuous endothelium and the distance between the capillary EC and the nearest cardiomyocyte is about $1 \mu \mathrm{m}$ leading to an optimal diffusion of oxygen and nutrients between blood and underlying cells. Like the endocardium, ECs of myocardial capillary are involved in reciprocal signalling with cardiomyocytes [5]. Moreover, cardiac microvascular ECs have been shown to promote cardiomyocyte survival [27]. In the endocardium the expression of von Willebrand factor and endothelial nitric oxide synthase (eNOS) is higher with respect to myocardial microvessels $[28,29]$ and eNOS is greatly concentrated in the Golgi body, whereas in myocardial capillary ECs, eNOS is more diffusely distributed in the cytoplasm $[5,30]$.

At cardiac valve level, there are two most prominent cellular components: the valve endothelial cells (VECs) and the interstitial cells. The VECs reside along the entire surface of the cusps or leaflets and are in continuity with endocardium, aorta, and pulmonary artery. The valve interstitial cells, however, make up the collection of mesenchymal cells that reside within specialized extracellular matrix subcompartments, fibrosa, spongiosa, and ventricularis/atrials layers. An extensive study of human VECs, on specimens ranging from 3 weeks gestation to 10 years of age, showed their progressive elongation and flattening on the ventricular side of the cusps, whereas VECs along the arterial side appeared cuboidal. ECs lining cardiac valves exhibit many of the same properties of ECs [31].

\section{Morphological and Structural Features of Endothelium}

The membrane of ECs is made of a double layer of phospholipids separated by water compartments and crossed by complex proteins that work as receptors or channels. ECs possess various contractile proteins, such as actin, myosin, and tropomyosin, that allow motor activities [32]. Some of these proteins are organized in a cortical web that surrounds the internal surface of the sarcolemma and defined ECs shape and elasticity. The junctions associated to actin filament, defined FAU system, are at the intercellular level and their contraction and relaxation control the dimension and hence the shape of the intercellular space, modulating the passage of solutes and macromolecules between blood and subendothelial space. The FAU system is closely related to the intercellular adhesion molecules, especially with vascular endothelial (VE) cadherin, maintaining a balance between adhesive and contractile forces [32].

ECs have three surfaces: cohesive, adhesive, and luminal. The cohesive surface adjoins ECs with each other and facilitates transport processes and consists of specialized intercellular junctions: gap, tight, or adherent junctions and syndesmos $[33,34]$. The adhesive surface of ECs adheres to basal lamina and, finally, the luminal side of the vascular endothelium consists of molecules and specific binding proteins regulating trafficking of circulating blood cells [34].

ECs and their nuclei are aligned in the direction of blood flow in straight segments of arteries, but not at branch points $[3,35,36]$. When blood flow increases and so also shear stress, the ECs are flattened and aligned in the direction of the flow; whereas when blood flow decreases the ECs increase their volume losing the alignment and looking like cobble stones paving [32]. The ECs are, in fact, sensitive to changes of the intravascular tension and may increase their stiffness after the increment of the intravascular pressure.

Bevilacqua et al. [37] identified the first inducible endothelial cell-specific leukocyte adhesion molecule (ELAM-1), later designated as endothelial cell-selectin (E-selectin) [7, 38]. Considering the potential ECs markers, PECAM-1 is, in addition, expressed in monocytes; thrombomodulin as well as in ECs, is also expressed in keratinocytes, trophoblasts and leukocytes and VE-cadherin is expressed also in trophoblasts and fetal stem cells. Moreover, it is known that ECs may express also vascular endothelial growth factor (VEGF) that plays a key role in the generation and maintenance of endothelial fenestrae [3] and eNOS, whose expression increases after higher shear stress, inducing the parallel sustained increase in the production of nitric oxide (NO) [1,39]. This free radical is the key endothelium-derived relaxing factor that plays a pivotal role in the maintenance of vascular tone and reactivity. In addition to being the main determinant of basal vascular smooth muscle tone, $\mathrm{NO}$ acts to negate the actions of potent endothelium-derived contracting factors, such as angiotensin II and endothelin-1 (ET-1). In addition, NO serves to inhibit platelet and white cell activation and to maintain the vascular smooth muscle cells in a nonproliferative state (Figure 1) [40].

Endothelium is also the source of the potent vasoconstrictor peptide ET-1. First isolated, purified, and sequenced in 1988 [41], in health, the production of ET-1 is minimal and it is effectively opposed by NO and other endothelium derived vasodilators [42]. The circulating level of this short peptide was quickly determinant in humans and it was reported that, in most cardiovascular diseases, circulating level of ET-1 was increased [43]. Our research group observed a significative increase of ET-1 expression at aortic level in different animal models: rats with a severe nephrotoxicity induced by cyclosporine A $[44,45]$, rats with vascular damage-induced by nicotine [46], and in atherosclerotic mice (ApoE-deficient mice) [47]. Molecular data and in vitro and in vivo findings [48-50] have indicated that angiotensin II can turn on transcription of the precursor of ET-1 gene and biosynthesis of ET-1 in different cell types, including cultured vascular smooth muscle cells $[51,52]$ and ECs by acting on 


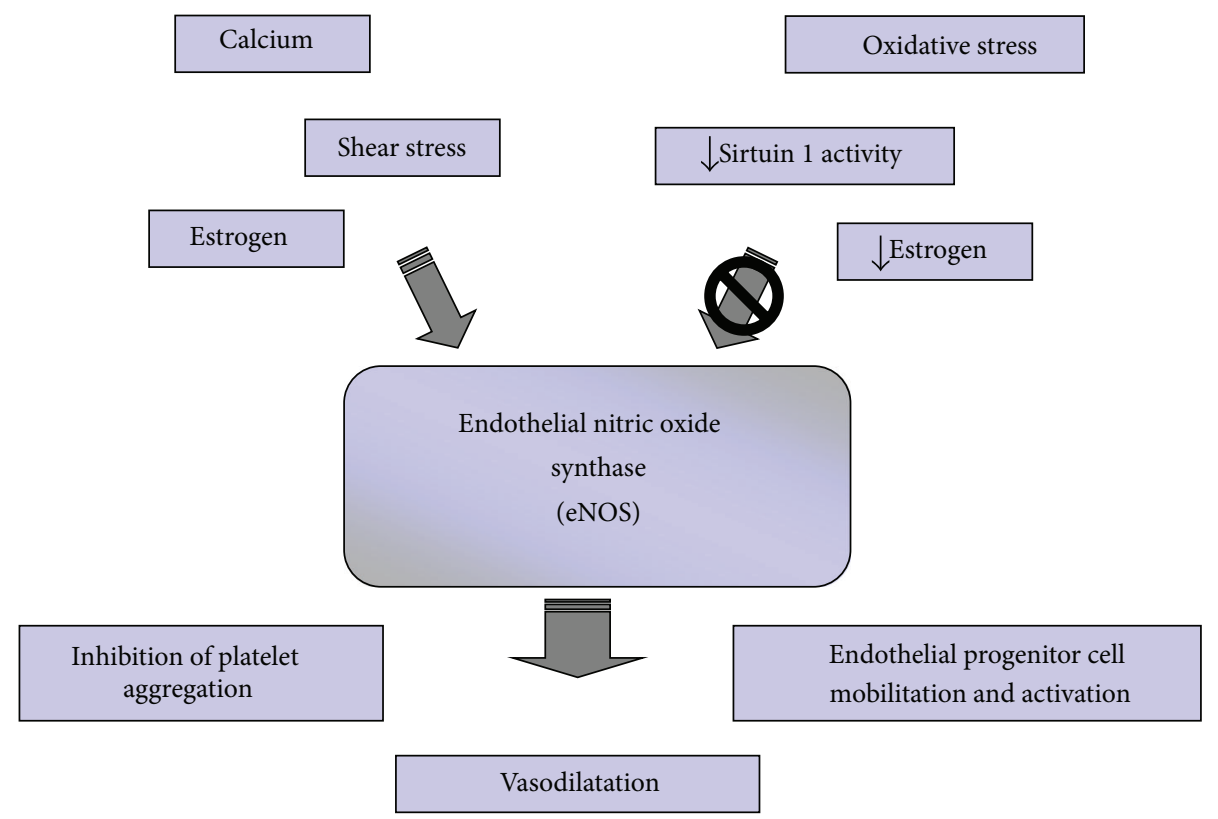

FIGURE 1: The activation of endothelial nitric oxide synthase (eNOS) may be induced by shear stress, estrogens, or increase of intracellular $\mathrm{Ca}^{2+}$ concentration and may be inhibited, mainly during aging physiopathological process, by oxidative stress and reduction of Sirtuin 1 activity and of estrogens level. In healthy endothelium, eNOS plays multiple functions, such as nitric-oxide vasodilation and inhibition of platelet aggregation and may induce endothelial progenitor cells activation and functions.

angiotensin II type 1 receptors. ET-1 might be also involved in the cardiovascular damage because it was found to contribute to hypertrophic response to angiotensin II $[50,53,54]$.

Platelet-selectin (P-selectin) is expressed not only in ECs but also in megakaryocytes; it is stored intracellularly in Weibel-Palade bodies and it is expressed preferentially in postcapillary venules $[3,55]$. Unlike E-selectin and P-selectin, intercellular adhesion molecule-1 (ICAM-1) and vascular cell adhesion molecule-1 (VCAM-1) are expressed in many vascular and nonvascular cell types. Constitutive expression of cell surface VCAM-1 in mice is generally lower than that of ICAM-1, with the exception of heart, where both are equally expressed, and brain in which VCAM-1 density is 4-fold higher with respect to ICAM-1 [3]. It is well known that the expression of ICAM-1 and VCAM-1 is strictly connected and correlated to atherogenesis $[2,3,56]$.

The superoxide dismutase (SOD) enzymes are also a key determinant of NO bioavailability since SOD competes with NO for superoxide in a diffusion-limited manner, thus attenuating the formation of peroxynitrite and, indirectly, improving NO bioavailability $[57,58]$. Indeed, in mice with a genetic ablation of the cytosolic isoform SOD1, endothelial dysfunction was associated with increased superoxide and peroxynitrite levels compared with wild type controls. Furthermore, exogenously added SOD was able to partially restore endothelium-dependent vasodilation in an eNOSdependent manner $[58,59]$. In addition, overexpressing the mitochondrial isoform SOD2, specifically in the endothelium of streptozotocin-induced diabetic mice, prevented diabetic retinopathy and superoxide-mediated oxidative stress [60]. These data clearly demonstrate the important role of SOD that plays a role in balancing oxidative stress through removal of superoxide and thereby maintaining NO levels [58].

Endothelial expression of tissue factor has been reported in certain pathologic conditions, including tumors [61], atherosclerosis [62], sickle cell anemia [63], sepsis, and cardiac allograft rejection [64]. It is possible that under these conditions endothelial tissue factor plays an important pathogenic role and that an understanding of its transcriptional regulation would provide new insights into mechanisms of disease [2].

3.1. Cellular Junctions. Two main types of intercellular junctions are recognized in ECs: tight junctions, defined also as zona occludens, and adherens junctions, also termed as zona adherens $[3,65,66]$. The junctional composition of intercellular clefts varies across the vascular tree. The tight junctions, which are usually found at the apical region of the intercellular clef, impart two functions in the cell: a barrier function, regulating the permeability of solutes between adjacent cells, and a function controlling the lateral diffusion of proteins within the lipid bilayer [67-69]. The ECs of large artery display a well-developed system of tight junctions due to their conduit function and their exposure to high rates of pulsatile blood flow, whereas in the arterioles the junctions are tighter with respect to capillaries and are quite loose in venules [3]. The extracellular membrane-bound components of the tight junctions are formed by proteins from three families: claudins, occludins, and junction adhesion molecules [70-73].

The identification of several components of adherens junctions in ECs helps in the understanding of the complex 
role of these structures not only in maintaining cell-tocell adhesion but also in transferring intracellular signals. VE-cadherin is an endothelial-specific adhesion protein at adherens junctions that interacts with several signalling partners inducing contact inhibition of growth and decrease in permeability.

Several pathological conditions have been associated with altered junction organization including chronic inflammation, atherosclerosis, or tumor angiogenesis. In these cases, altered junctions are likely the consequence of vascular injury or EC activation and retraction [74].

3.2. Caveolae. In physiological condition, there are various ways of transporting plasmatic molecules through the endothelial barrier: (i) intercellular unions that generally act as filters controlled by the hydrostatic pressure that allow the passage of water and dissolved substances; (ii) vesicles formed from the caveolae that help the passage of macromolecules through the cell membrane and cytoplasm; (iii) transcellular channels usually formed from various caveolae that connect opposite sides of the cell membrane. In particular, through caveolae, the endothelium regulates the passage of fluid and macromolecules between the vascular and cellular compartments; when this way fails, there is the formation of edema [32].

Caveolae are $70 \mathrm{~nm}$ membrane-bound, flask-shaped vesicles that are usually open to the luminal or abluminal side and are occasionally free in the cytoplasm [3]. Caveolae occupy between $5 \%$ and $10 \%$ of the total EC surface [32, 75]. The number of caveolae is the highest in continuous nonfenestrated endothelium, particularly at heart, lung, and skeletal muscle levels [3], whereas in the blood brain barrier the caveolae are rarely found [15]. It is important to remember that caveolae are present also in non-ECs.

There are three caveolin (cav) isoforms, cav-1, cav-2, and cav-3. Cav-1 and cav-2 are ubiquitously expressed, whereas cav-3 is specific for striated muscle. Cav-1 and cav-3 have a conserved cav scaffolding domain, which is bound by many membrane proteins, such as $\mathrm{G}$ proteins, tyrosine kinase receptors, and eNOS [76, 77]. Cav-1 and cav-2 are expressed in most cell types including all cell types of the cardiovascular system, while cav-3 is expressed prevalently in cardiac and skeletal muscle [78].

Cav-1 is the main caveolae found at the endothelial level [58]; various EC signalling molecules localize in caveolae and are modulated by direct interaction with cav-1 $[58,79]$. NO production, by eNOS, is tightly regulated by enzyme interaction with cav-1 $[80,81]$. Cav-1 has been shown to directly bind eNOS and inhibit eNOS-derived NO release under physiological conditions [82]. On the contrary, for optimal NO release, eNOS must reside in caveolae microdomains [58]. Interestingly, also members of the transient receptor potential channel (TRPC) family reside in caveolae [81, 83, 84].

Our previous study demonstrated that the genetic deletion of cav-1 in mice results in total absence of endotheliumderived hyperpolarizing factors- (EDHF-) mediated vasorelaxation altering calcium $\left(\mathrm{Ca}^{2+}\right)$ entry and disregulating the expression and caveolar location of connexins and myoendothelial and vascular homocellular gap junction components [81]. EDHFs, including NO, carbon monoxide, hydrogen sulphide, lipoxygenase, and others, regulate cellular hyperpolarization decreasing $\mathrm{Ca}^{2+}$ influx, either by reducing the open probability of cave channels or the cav channeldependent activation of the sarcoplasmic reticulum, which induces relaxation of vascular smooth muscle cells $[85,86]$.

Cav-2 is expressed in ECs, smooth muscle cells, skeletal myoblasts, fibroblasts, white adipocytes, lung tissue, and pancreatic islets. When compared to human cav-1, cav- 2 was determined to be roughly 38\% identical and 58\% similar to a conserved region of eight identical aminoacids. It is important to underline that cav-2 is able to directly bind cholesterol without cav-1 interaction [87].

However, cav-3 is roughly $64 \%$ identical to cav- 1 and can form homooligomeric complexes with itself and does not require cav-1 to drive caveolae formation [88]. In cardiomyocytes, eNOS localizes to caveolae binding to cav-3. The colocalization of cav-3 and eNOS may facilitate both eNOS activation by cell surface receptors and NO release at the cell surface for intercellular signaling $[89,90]$.

3.3. Transient Receptor Potential Channel. There are six TRPC proteins in humans, but more TRPCs may arise through heteromerization among TRPCs and other types of transient receptor protein. TRPCs support endothelial functions like vascular regeneration, increased permeability, and endothelium-derived NO-mediated vasorelaxation playing a central role in the control of vascular smooth muscle cell tone, endothelial permeability, and platelet function. Some of these ion channels are relatively $\mathrm{Ca}^{2+}$ selective but many are nonselective cationic channels with permeability to $\mathrm{Ca}^{2+}$, sodium $\left(\mathrm{Na}^{+}\right)$, and potassium $\left(\mathrm{K}^{+}\right)$. In a few instances they are $\mathrm{Ca}^{2+}$-impermeable or permeable also to magnesium and other cations (Figure 2). All of the TRPCs are reported to be expressed in blood vessels, especially in ECs and vascular smooth muscle cells. They are functionally important, but almost not critical for the development or maintenance of a physiological vasculature [91].

A careful comparison of EC responses from different TRPC-deficient mice with respect to wild type mice permit to identify which channel(s) is/are essential for modulating the changes in vascular permeability [92].

Freichel and colleagues [93] observed, in primary aortic ECs of TRPC4 $4^{-1-}$ mice, that TRPC4 is part of the $\mathrm{Ca}^{2+}$ influx signal transduction pathway regulating vascular tone. However, TRPC5 might also be involved in this process; in fact, the treatment of bovine aortic ECs with siRNA against TRPC5 prevented NO-induced $\mathrm{Ca}^{2+}$ entry and so decreased endothelium-dependent NO vasorelaxation [94]. A TRPC5 and 6 activation cascade have been shown to take part in the regulation of ECs migration $[92,95]$. However, inhibition of TRPC3 activity by protein kinase G-dependent phosphorylation was observed to protect ECs from the detrimental effect of excessive $\mathrm{NO}$ and $\mathrm{Ca}^{2+}[92,96,97]$. In particular, TRPC3 channels have been suggested to serve as redox sensors which monitor oxidative stress in ECs. However, TRPC3 may not be 


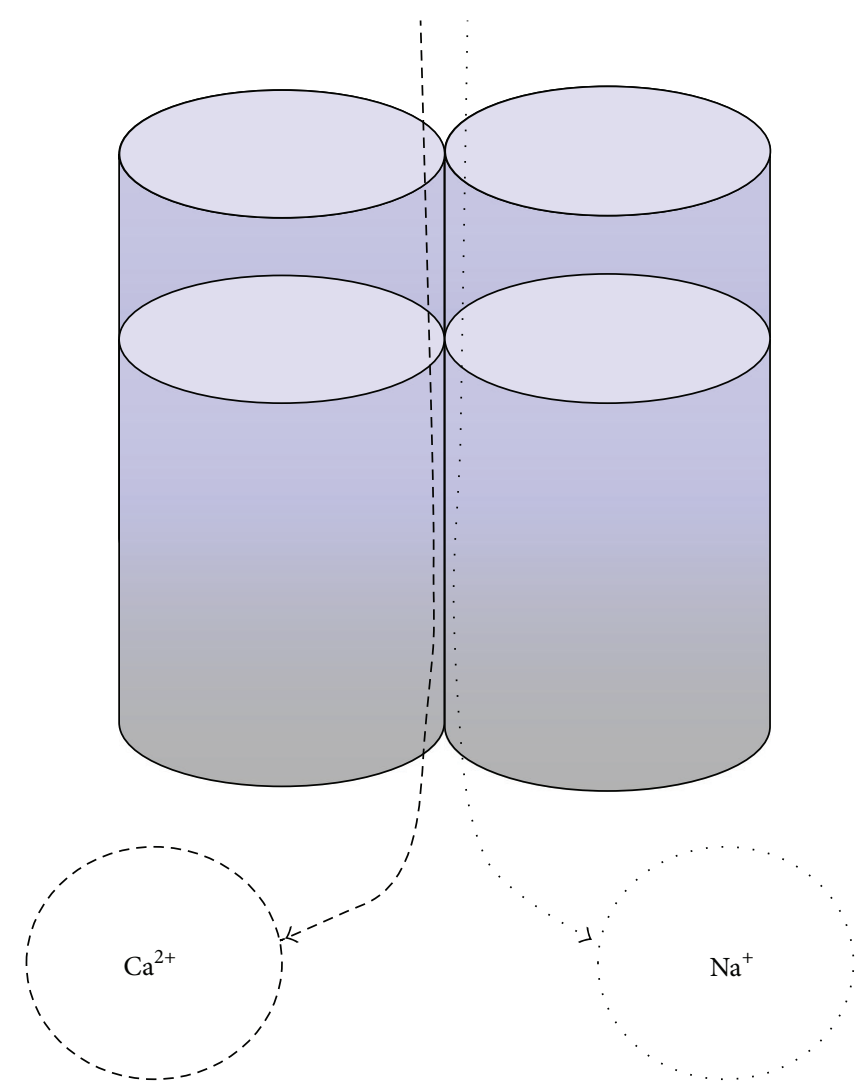

FIGURE 2: Transient receptor potential channels (TRPCs) clustered around a central ion pore enabling influx of calcium and sodium ions. $\mathrm{Ca}^{2+}$ : calcium; $\mathrm{Na}^{+}$: sodium.

acting alone in this process; in fact the heteromeric channels composed of TRPC 3 and 4 form redox-sensitive channels both in native ECs and when being heterologously expressed in human embryonic kidney 293 (HEK293) cells [98, 99].

Nevertheless, the exact role of these channels is still under study. TRPCs may therefore be attractive drug targets to tackle physiopathological states; therapeutic approaches to modulate activation of specific TRPCs are likely to have an important impact in reducing tissue damage in a number of diseases resulting from oxidant stress including ischemia/reperfusion injury, hypertension, edema, bleeding disorders, and diabetes $[92,99]$.

\section{Endothelial Progenitor Cells}

Endothelial progenitor cells (EPCs) are bone marrow-derived stem cells that differentiate into functional ECs [100-103]. EPCs are mobilised from the bone marrow into the peripheral blood in response to tissue ischemia or injury [104]. EPCs migrate to vascular or tissue injury sites, contributing significantly to reendothelialization and neovascularization and hence tissue repair [105-108] and differentiate into ECs [109]. However, a reduction in the number of circulating EPCs may also result in the impaired reendothelialization of eroded atherosclerotic plaque and thus lead to a greater propensity for thrombosis and vascular occlusion. Several lines of evidence indicate that EPCs constitute an important endogenous system that maintains endothelial and vascular integrity [103].

Moreover, EPCs may play an important role in maintaining an intact and functional endothelium in mature blood vessels and the alteration of this function leads to abnormal vasoreactivity [101]. It was observed by Vasa and colleagues [110] that the number and migratory activity of circulating EPCs decreased in patients with risk factors for coronary artery disease, suggesting that a decrease in the EPCs level may contribute to impaired vascularization. EPCs have been also implicated in postischemic neoangiogenesis $[111,112]$ and are ideal candidates for vascular regeneration $[113,114]$. De Ciuceis and colleagues [115] observed that EPCs and capillary density were reduced in obese subjects, but pronounced weight loss induced by bariatric surgery significantly increased EPCs and seems to induce an almost complete regression of microvascular fibrosis, while not improving capillary rarefaction. Further clinical studies are needed to amplify the knowledge about EPC mobilization and function and for the establishment of EPC measurements as prognostic markers in cardiovascular diseases.

\section{Endothelial Cells Functions}

The endothelium exerts its function in maintaining vascular homeostasis through the balanced release of a number of autocrine and paracrine substances in response to physical, biological, and chemical stimuli [1]. In fact, it is known that the endothelium plays an important role in many physiological functions, including the control of vascular tone, blood cell trafficking, innate and adaptive immunity, and hemostasis [3]. Endothelium is capable of producing vasoactive factors, such as vasodilators and vasoconstrictors, procoagulants and anticoagulants, inflammatory and antiinflammatory factors, fibrinolytics and antifibrinolytics, oxidizing and antioxidizing, and other factors $[32,116,117]$.

The endothelium regulates vascular tone via responding to a variety of stimuli [118]. This process involves a complex interplay between intracellular receptors, the synthesis, and then the release of a variety of endothelium-derived relaxing and constricting substances $[119,120]$.

Passage of leukocytes from blood to underlying tissue through the endothelial layer involves a multistep adhesion pathway that includes rolling, initial attachment, arrest, and transmigration. These steps take place prevalently in postcapillary venules. In particular, rolling is mediated primarily by interactions between leukocyte carbohydrate-based ligands and endothelial E- and P-selectin and firm adhesion by interactions between leukocyte integrins and ICAM-1 and VCAM-1. There are two pathways for the passage of leukocytes through the endothelial layer: they may pass between ECs, paracellular route, or they may pass through the EC itself, defined as transcellular route $[17,121,122]$. The molecular basis of transmigration is actually controversial, but it is known that it involves CD99, PECAM-1, and junctional adhesion molecule-1 $[3,123,124]$. 
Another common function of the endothelium is the capacity to maintain blood in a fluid state limiting clot formation when there is a breech in the integrity of the vascular wall and the endothelium serves as a borderline between the coagulation factors circulating in the blood and the primary initiator of coagulation within the vascular wall $[86,125,126]$.

ECs express tissue factor pathway inhibitor, heparan, thrombomodulin, endothelial protein $\mathrm{C}$ receptor (EPCR), tissue-type plasminogen activator, ecto-ADPase, prostacyclin, and NO, as anti-coagulant factors, whereas ECs may synthesize tissue factor, plasminogen activator inhibitor1 , von Willebrand factor, and protease activated receptors (PARs), as procoagulant factors [3, 127]. EPCR is expressed predominantly in large arteries and veins [128], whereas thrombomodulin is highly expressed in blood vessel types of every calibre in all organs, with the exception of the brain, where its expression is low $[3,129]$. The differential distribution of procoagulants and anticoagulants in the vessel tree suggests and confirms the endothelial heterogeneity and that ECs from different sites of the body use site-specific procoagulants or anticoagulant factors to balance specific and local haemostasis [7].

Other important functions of the endothelium are to regulate the transport of liquids across the semipermeable vascular endothelial barrier $[92,125]$ and function as a protective biocompatible barrier between all tissues and the circulating blood, hence modulating the bidirectional passage of macromolecules and blood gases to and from tissues and blood [41]. Importantly, these properties vary both in space and time, once and again giving rise to the phenomenon of EC heterogeneity $[2,130]$. In Figure 3 the main functions of endothelium are summarized.

Given the critical role of these mechanisms in which ECs are the key factors, the deregulation of the endothelial balance, defined endothelial dysfunction, leads to the pathogenesis of many diseases including atherosclerosis, hypertension, sepsis, and some inflammatory syndromes [1, 40].

\section{Endothelial Dysfunction}

As described in the previous paragraphs, the endothelium is an emergent and complex system. It is multifunctional, highly distributed in space, and has an enormous behavioural repertoire; in fact EC dysfunction is not restricted anatomically to a single organ or limited in a singular disease mechanism $[3,7]$. The ECs represent a powerful organizing system in human health and disease, also because they are involved in numerous pathological states either as primary determinants of physiopathology or as victims of collateral damages $[5,7]$.

Endothelial dysfunction disrupts the mechanism of vascular homeostasis regulation predisposing the vessel wall to vasoconstriction, leukocyte adhesion, platelet activation, oxidative stress, thrombosis, coagulation, and inflammation hence leading to the pathogenesis of cardiovascular diseases $[40,131]$.
Early description of EC dysfunction focused on structural changes or loss of anatomical integrity, particularly in the context of atherosclerosis: Ross and Glomset [132] proposed, in 1973, a response-to-injury hypothesis to explain the lesions of atherosclerosis. Then, Bevilacqua et al. [37] employed the term EC dysfunction to describe hyperadhesiveness of the endothelium to platelets.

It is important to underline that EC may be activated without being dysfunctional [7] and that endothelium is highly active and constantly sensing and responding to alterations of the local extracellular environment [133]. The term "activation" reflects the capacity of ECs to perform new functions without evidence of cell injury or dysfunction [134].

It is well known that the intact endothelium may actively contribute to disease initiation and/or progression. The transition between EC function and dysfunction is not always clear. EC dysfunction usually arises from otherwise adaptive responses that are now excessive, sustained, or spatially and/or temporally misplaced [7]. Moreover, the endothelium is heterogeneous in its response to physiopathological stimuli [133].

The concept of EC activation first arose from in vitro studies demonstrating the ability of well-defined stimuli to induce the expression of the so-called "activation antigens" on the surface of ECs; actually, P-selectin is considered a marker of EC activation [135].

In conclusion, the endothelium is highly plastic and thus amenable to therapeutic modulation, in establishing a dialogue with the underlying tissue and so it provides a possible direct line of communication with every organ in the body. The goal in treating the endothelium is not to reset the switch, but rather to fine-tune and recalibrate the EC, nudging back to their physiological state [133]. Given that EC phenotypes vary according to time and location in the vascular tree, in both health and disease states, it is essential to modulate therapy to specific vascular beds.

In the following paragraphs, the main EC dysfunction observed at cardiovascular level in the pathological states of atherosclerosis, hypertension, diabetes, and cardiac valvular degeneration or induced by age or cigarette smoking was summarized. Successively, we will briefly present a possible emerging prevention/treatment of ECs dysfunction through a healthy lifestyle.

6.1. Atherosclerosis. Endothelial dysfunction is known to be implicated in the pathogenesis and clinical course of all known cardiovascular diseases $[136,137]$, occurs in response to cardiovascular risk factors, and precedes the development of atherosclerosis [42, 138, 139]. Endothelial dysfunction actively participates in the process of lesion formation promoting the early and late mechanisms of atherosclerosis $[32,40,42]$, determining increase in EC permeability, upregulation of adhesion molecules, chemokine and cytokine secretion, and leukocyte adherence, enhanced oxidized-low density lipoprotein (ox-LDL), platelet activation, and vascular smooth muscle cell proliferation and migration. In addition, endothelial dysfunction is not only the initial stage of the development of atherosclerotic disease that generates 


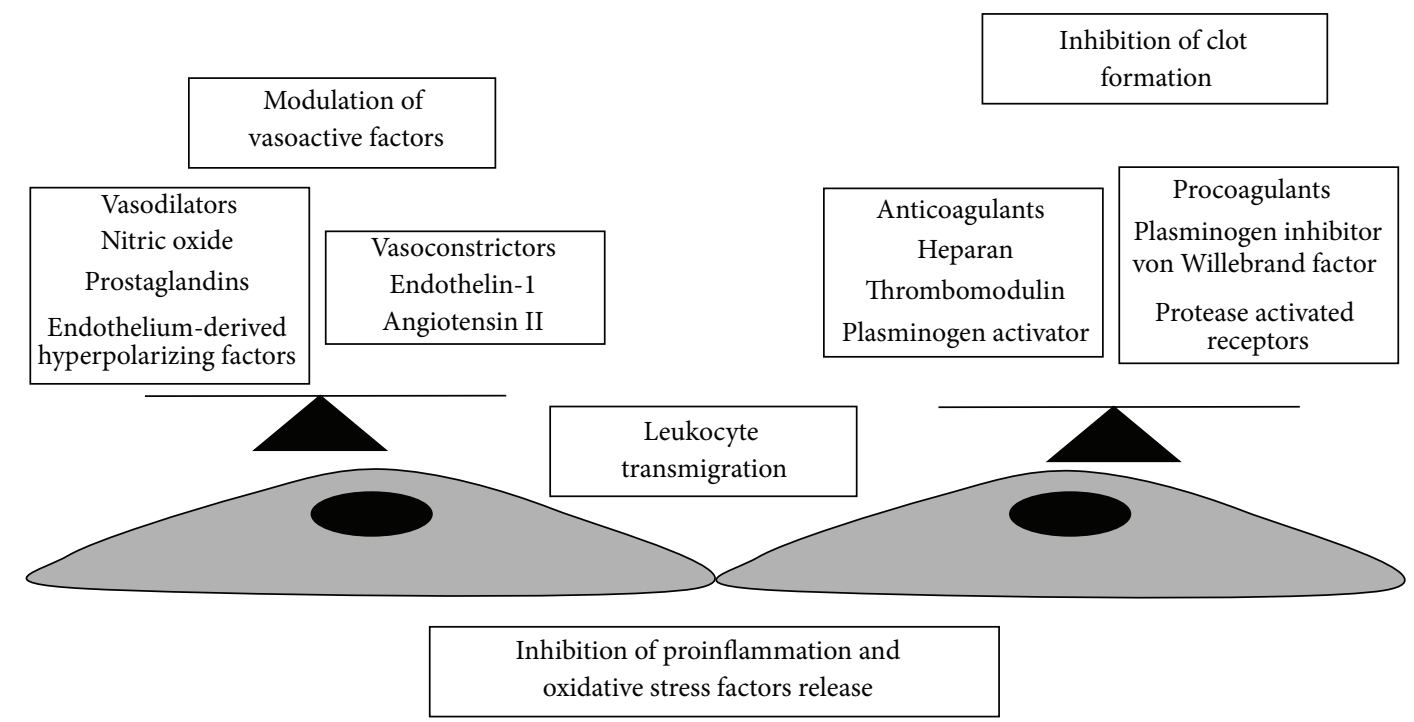

FIGURE 3: Endothelial functions in physiological conditions. The net balance of endothelium-derived vasodilators and vasoconstrictors or anticoagulants and procoagulants along with inhibition of proinflammatory and oxidative stress factors release and leukocyte adhesion and transmigration maintain a healthy vascular homeostasis.

plaque formation, but it also can cause plaque growth leading to vascular complications. For all these reasons, endothelial dysfunction is one of the principal mechanisms in atherosclerotic diseases [32].

The endothelial injury, activation, and dysfunction caused by ox-LDLs in the pathogenesis of atherosclerosis are exerted via the activation of lectin-like ox-LDL receptor-1 (LOX-1) activation [100, 140]. LOX-1, initially identified as the major receptor for ox-LDL in ECs, can also be expressed in macrophages and smooth vascular muscle cells [101, 141143]. LOX-1 has the ability to bind damaged or apoptotic cells, activated platelets, advanced glycation end products, and pathogenic organisms $[144,145]$ and so it may play a role in initiating and potentiating the early steps of atherogenesis. However, elevated LOX-1 expression is observed not only in both initial and advanced atherosclerotic lesions [101, 143, $146,147]$ but also during other cardiovascular injuries, such as hypercholesterolemia, hypertension, obesity, and diabetes $[140,148]$. Ox-LDL, via upregulation of LOX-1 mediated by angiotensin II and ET-1, induces monocyte adhesion to the endothelium via enhanced expression of P-selectin, ICAM1 , and VCAM-1 $[149,150]$. Receptor activation also results in monocyte chemoattractant protein-1 expression, promoting monocyte migration into the intima $[101,151]$. However, oxLDL uptake by LOX-1 also mediates EC apoptosis, potentially via nuclear factor $(\mathrm{NF})-\kappa \mathrm{B}$ activation $[101,152]$ and resulting in direct vascular denudation and injury that may trigger or enhance the inflammatory and oxidative stress reactions. Ox-LDL binding to LOX-1 induces an increase production of intracellular reactive oxygen species (ROS), apoptosis of vascular smooth muscle cells, and modulation of matrix metalloproteinase activity, all factors/conditions that compromise and alter the atherosclerotic fibrous cap. Moreover, activated platelets may interact with the surrounding endothelium via LOX-1 [153] promoting the release of ET-1 from ECs, stimulating the generation of ROS that inactivates NO [145] and so starting a vicious circle that potentially ends in vascular occlusion and ischemic insult.

ECs are involved in the atherogenic process also through PAR expression. EC PAR-1 activation promotes adhesivity toward monocytes via the induction of NF- $\kappa \mathrm{B}$, which in turn promotes ICAM-1 expression [101, 154]. PAR-1 and PAR-2 activity induces discharge of Weibel-Palade bodies and endothelial storage granules containing the adhesion molecule P-selectin and von Willebrand factor, promoting both leukocyte and platelet adhesion [101, 155]. PAR activation is also linked to the secretion of interleukins and cytokines that promote C-reactive protein synthesis that, itself, triggers many of the steps in the inflammatory process so enhancing the initiation and progression of atherosclerotic plaques [156]. Moreover, atherogenesis progressively impairs endothelial vasoactive function, ranging from impaired endothelium-dependent vasodilatation in conduit and resistance of vessels in patients with hypercholesterolemia to complete loss of endothelium-dependent vasodilation in patients with histologically proven atherosclerotic lesions [157-160].

Lipid-lowering diet $[161,162]$ and lifestyle modification $[163,164]$ have been shown to restore or improve impaired endothelium-dependent vasodilation in the atherosclerotic disease state [160].

6.2. Hypertension. Arterial hypertension is the most prevalent risk factor associated with increased cardiovascular morbidity and mortality [165]. The hypertensive vascular dysfunction, characterized by endothelial dysfunction and hypertensive remodelling of vascular smooth muscle cells, are well known and described processes. The complicated mechanisms underlying vascular dysfunction involve decreased 
NO bioavailability, activation of the pathways of vascular smooth muscle contraction, vascular oxidative stress, and inflammation [166-169]. The impaired endotheliumdependent vasodilatation in hypertension is characterized by an imbalance between EC derived vasodilatant and vasoconstrictor factors [170-172]. Oxidative stress is important in the development and maintenance of hypertension, in terms of excess production of oxidants, decrease in NO bioavailability, and antioxidant capacity in the vasculature $[169,173]$. Moreover, the prevalence of hypertension markedly increases with advancing aging. Although aging and hypertension, either independently or collectively, impair endothelial function, they may have similar cascades for the pathogenesis and development of endothelial dysfunction [174].

At this regard, reductions in both vascular oxidative stress and inflammation have been shown, also by our research group, that reverse endothelial dysfunction through the administration of antioxidants, such as melatonin or pycnogenol, in an experimental model of genetic hypertension [175-177].

6.3. Diabetes. Diabetes, characterized by persistent elevation of blood glucose levels (hyperglycaemia), occurs due to inadequate production of insulin (type 1 diabetes) or resistance to endogenous insulin usually associated with metabolic syndrome and obesity (type 2 diabetes).

Endothelial functions impaired in metabolic syndrome could reduce insulin access to the tissue and thus decrease insulin sensitivity independently from direct effects at the muscle cells [178]. In type 1 diabetes, endothelial dysfunction is predominantly triggered by the metabolic changes related to hyperglycemia and microvascular complications, but prevalently at retinal and kidney levels [179]. In type 2 diabetes, the link between endothelial dysfunction and diabetes is more complex, as endothelial dysfunction starts well before the onset of diabetes [180-182].

In insulin resistance and diabetes, a variety of endothelial functions is compromised, including regulation of vascular tone $[182,183]$ and organ perfusion $[184,185]$, inhibition of inflammation $[182,186]$, transendothelial transport of blood solutes $[182,186]$, prevention of coagulation $[178,185]$, and initiation of angiogenesis $[187,188]$.

Moreover, it has been shown that impaired endotheliumdependent vasorelaxation is linked to increased cav-1 protein expression in the aorta of diabetic rats. This was attributed to an inhibition of eNOS function due to cav-1 binding and a reduction of NO production $[189,190]$.

The endothelial insulin signalling is significantly impaired after a high fat diet, coinciding with a reduction in insulin-induced capillary recruitment and reduced interstitial insulin. Thus, it suggests that the endothelial insulin signalling required for delivery of insulin to the interstitial space can be inhibited physiologically by diet [178].

Recent studies have observed that hyperglycemia caused mitochondrial fragmentation and altered mitochondrial dynamics, associated with increase in mitochondrial ROS production [191] and so could cause a rapid breakdown in NO vascular tone regulation $[58,178]$. This impairment could be responsible for the endothelial dysfunction observed in diabetes; however, endothelial dysfunction is often evident prior to a significant elevation in plasma glucose levels and can be induced by factors other than hyperglycaemia [178, 192]. In Figure 4 are schematically summarized the main pathways activated during hyperglycaemia and low insulin level inducing diabetes-associated vascular diseases.

Adipose tissue, especially in the abdomen and around blood vessels, defined perivascular adipose tissue (PVAT) $[182,193]$, has been shown to control insulin sensitivity and endothelial function [194], especially insulin-mediated vasoreactivity [182, 195-199]. Adipose tissue secretes a wide variety of bioactive substances (adipokines) that act directly on vascular endothelium [200]. With regard to endothelial function, PVAT is increasingly recognized as a critical fat depot that regulates local vascular tone [168] and inflammation [182, 201, 202]. These functions appear impaired in obesity and type 2 diabetes $[168,184,203]$. The PVAT inflammation may not only contribute to endothelial dysfunction but also hypoperfusion of adipose tissue and the resulting hypoxia may also trigger inflammation and alter adipokine secretion hence leading to a dysfunctional modulation of vascular tone [182, 204, 205].

6.4. Cardiac Valvular Degeneration. Cardiac valve pathology may be associated with local expression of VCAM-1 and Eselectin [5, 206, 207]. There is also evidence that aortic valve stenosis is associated with angiogenic activation of valvular ECs. In Chalajour et al.s [208] study, normal valves were avascular, whereas stenotic aortic valves contained neovessels. ECs lining these neovessels were consistently positive for PECAM-1, but only a portion was positive for von Willebrand factor. The heart valve stimulated by myocardium signals may lead to ECs transformation in endocardial-mesenchymal cells, losing cell-cell contacts and invading the extracellular matrix so forming endocardial cushions. It is important to underline that only those ECs within this region are capable of responding to these signals [5].

Halcox and Quyyumi [209] showed that impaired endothelium-dependent vasodilatation in coronary arteries with established atherosclerosis induced vasoconstriction, which may result in reduced myocardial perfusion and myocardial ischemia. There are also evidences to suggest that abnormalities of endothelium-dependent vasodilatation contribute to the clinical syndromes of microvascular angina and coronary vasospasm [42].

6.5. Cigarette Smoking and Endothelial Dysfunction. Epidemiological studies suggest that cardiovascular diseases account for over one-third of deaths of cigarette smokers $[210,211]$. Nicotine exposure via chronic cigarette smoking is an emerging cause of cardiovascular disorders [212, 213]. Numerous studies suggest that exposure to cigarette smoke leads not only to EC and vascular smooth muscle morphological alterations, but also functional exchanges [214-216] as early events in the pathogenesis of cardiovascular disease induced by cigarette smoking [217]. Nicotine plays a key role in mediating these changes by decreasing $\mathrm{NO}$ generation and 


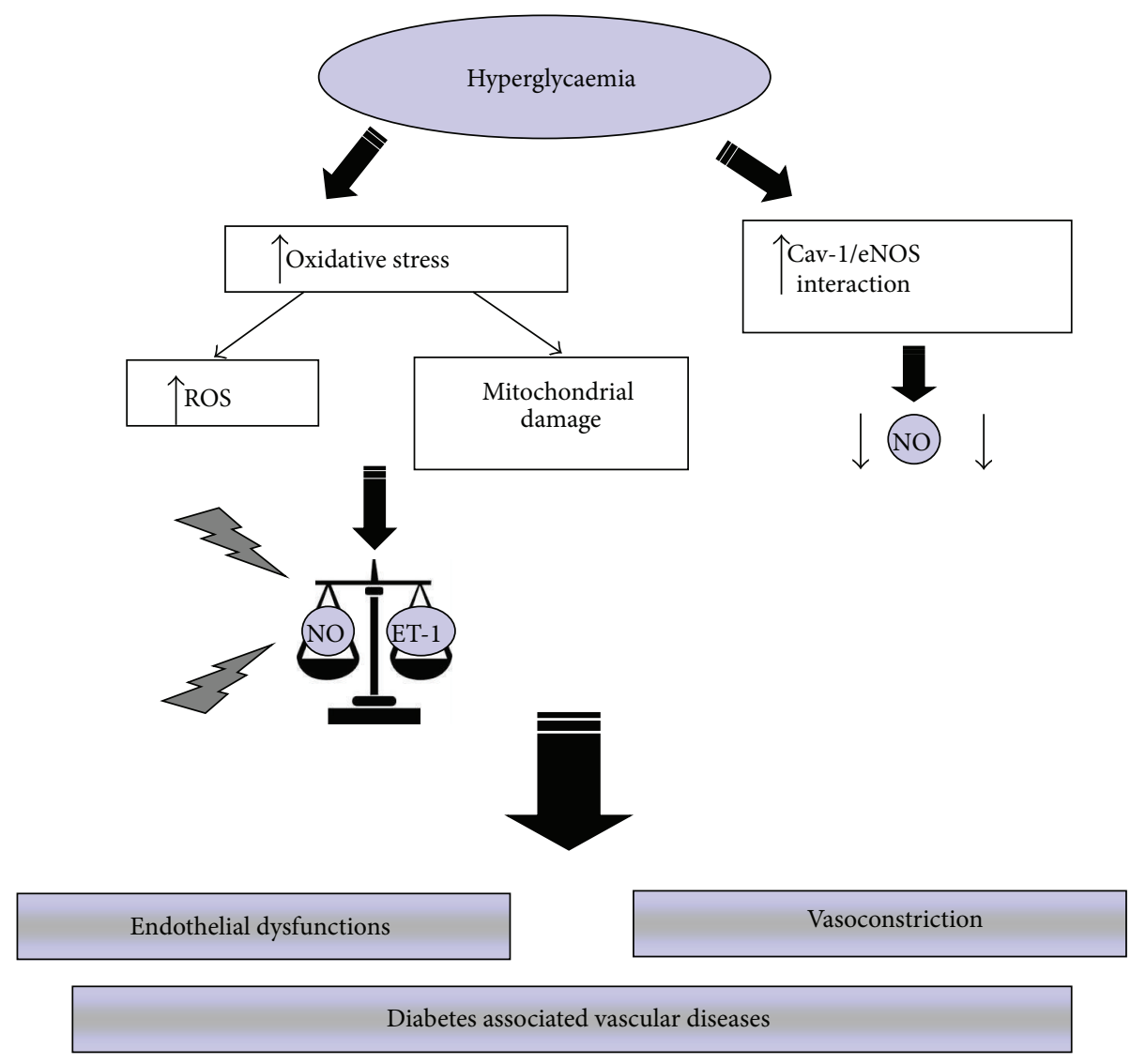

FIGURE 4: Main pathways activated during hyperglycaemia and low insulin level that alter the modulation of vascular tone, reducing nitric oxide, and increasing endothelin-1 release and so lead to endothelial dysfunction and diabetes-associated vascular disease. Cav-1: caveolin-1, eNOS: endothelial nitric oxide synthase; ET-1: endothelin-1; NO: nitric oxide.

bioavailability and downregulating the expression of eNOS (Figure 5) [218].

Furthermore, nicotine causes a loss of functional integrity of endothelium by causing vasospasm, stimulating the adhesion of platelets and leukocytes and promoting the formation of thrombus [219]. Our research group demonstrated that the administration of nicotine in rats depleted the bioavailability of NO, increased ROS, and damaged the structural integrity of aortic endothelium inducing cardiovascular disorders. The possible mechanism proposed to explain the damage of nicotine was the disruption of the physiological balance of vascular tone, the increased expression of ET-1, inducible NOS, and the reduced expression of eNOS and so NO and SOD [220, 221]. Furthermore, we observed both an increase in ICAM-1 and VCAM-1 expression that induced, in turn, the adhesion of monocytes and lymphocytes at EC level promoting the formation of the atherosclerotic lesion [46]. Nicotine may induce also the release of platelets derived growth factors, which promote the migration of vascular smooth muscle cells at the subendothelial space [222].

6.6. Aging and Endothelial Dysfunction. Aging is one of the main risk factors for the development of cardiovascular diseases and dysfunction at both endothelial and vascular smooth muscle cells. This dysfunction favours vasospasm, thrombosis, penetration of macrophages, cellular growth, oxidative stress, and inflammation leading to atherosclerosis and it is considered as a crucial event in the development of many vasculopathies [223]. Moreover, the aging process may deteriorate the balance between vasodilator and vasoconstriction substances produced by the endothelium [224-227]. This imbalance is mainly characterized by a progressive reduction of NO bioavailability and an increase in the production of cyclooxygenase-derived vasoconstrictor factors [223-227]. Both circumstances are in turn related to an increased production of ROS and reactive nitrogen species $[223,226]$. Free radicals play a physiological role in the vessel wall; in fact, they participate as second messengers in endothelium-dependent functions, vascular smooth muscle, ECs growth and survival, and in remodelling of the vessel wall [227, 228].

The presence of endothelial dysfunction in old people is associated not only with cardiovascular diseases such as atherosclerosis, coronary artery disease, diabetes mellitus, and arterial hypertension [228] but also with diseases related with aging as renal dysfunction [229], Alzheimer's disease [223, 230], circadian cycle alterations [231], erectile dysfunction [232], osteoporosis [223, 233], and retinopathy [234]. In addition, cell senescence plays a key action in the attenuated angiogenic and regenerative capacity of ECs with aging [223]. 


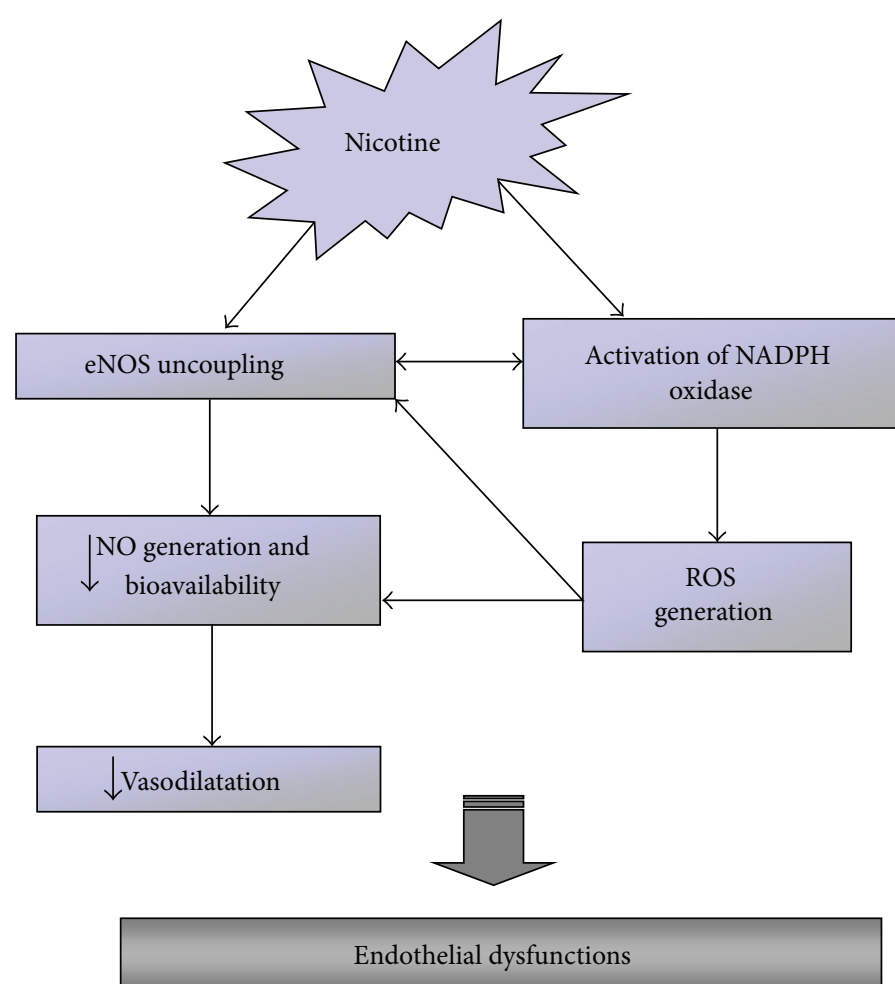

FIGURE 5: Schematic representation of endothelial dysfunction induced by chronic exposure to nicotine.

Senescent ECs showed a reduced proliferation that may limit the capacity to form new vascular structures. Interestingly, initial signs of endothelial senescence can even be found in young people $[235,236]$.

Several studies showed mitochondrial oxidative stress as a typical age-related endothelial dysfunction. This phenomenon is associated with the overactivation of nicotinamide adenine dinucleotide phosphate (NADPH) oxidase, an enzyme localized in the cytoplasm and in membranes of mitochondria [227, 237, 238]. Other molecular mechanisms responsible for age-related mitochondrial oxidative stress in the vasculature involve deregulation of antioxidant defences, such as peroxynitrite-mediated erythroid 2-related factor 2 (Nrf2) dysfunction, nitration and inhibition of SOD, decline in glutathione content, and a dysfunctional electron transport chain [227, 239]. Previous studies suggest that increased ROS in aging promotes mitochondrial protein oxidation and increased mitochondrial DNA mutations in heart and other organs, but it is yet to be determined whether similar aging-induced mitochondrial DNA and protein damages play an important role in ECs and vascular smooth muscle cells alterations. Furthermore, some evidences suggest that mitochondria-derived ROS contribute to accelerated development of the senescent phenotype in ECs. EC senescence may impair the physiological properties of the endothelium and may promote the progression of cardiovascular diseases by altering the secretion of cytokines, growth factors, and proteases in the vascular wall [240].

Inhibition of Sirtuin 1, a class III nicotinamide adenine dinucleotide- (NAD-) dependent protein deacetylases defined as longevity protein [47, 241, 242], induces premature senescence, whereas Sirtuin 1 overexpression reverts premature senescence induced at vascular level [227].

In our recent study, we observed that Sirtuin 1 is implicated in the development of age-related vasculopathy. Sirtuin 1 is not present in the vessels of apolipoprotein E-deficient mice at 6 weeks or 15 weeks of age. So, the studies provide a new insight into the atheroprotective effects of Sirtuin 1 and imply that Sirtuin 1 may be a potential target for the intervention in the atherogenetic process [47].

The main EC dysfunction induced by the physiopathological process of aging is summarized in Figure 6. Further studies are warranted to determine whether novel therapies that reduce mitochondrial oxidative stress and/or senescence of ECs are able to prevent the development of endothelial senescence and apoptosis, improve vasodilator functions, and prevent age vasculopathy [240].

\section{Prevention of Endothelial Dysfunction}

Various pharmacological therapies have been designed to reduce the development and progression of cardiovascular diseases, such as insulin sensitizers, statins, $\mathrm{Ca}^{2+}$ channel blockers, inhibitors of the rennin-angiotensin system, and antiplatelet agents [243-245]. However, strictly controlling cardiovascular risk factors is often difficult to obtain and the progression of pathological states has not been completely prevented with current pharmacological therapeutic options. Moreover, the modern evolution of Western societies seemingly steers populations towards a profound sedentary 


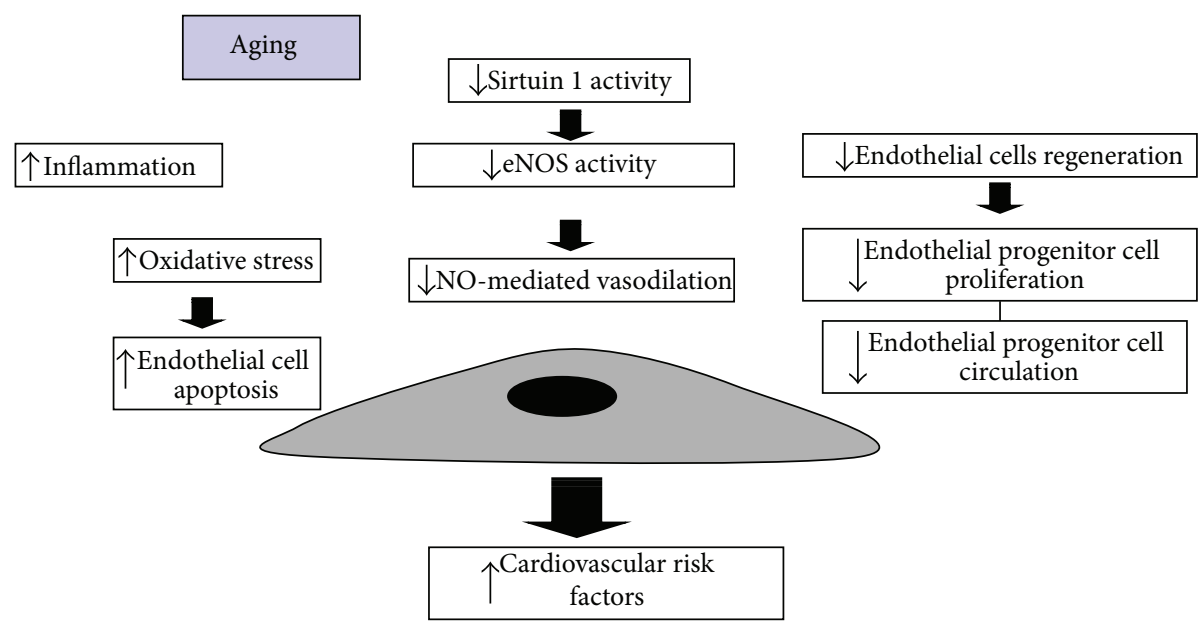

FIGURE 6: Schematic summary of the main age-related endothelial alterations.

lifestyle and incorrect diet is becoming difficult to reverse. Understanding the mechanisms that explain the fatal effects of physical inactivity and incorrect diet opposite to the beneficial effects of a healthy lifestyle remains largely unexplored $[243,246]$.

In the following paragraphs, we briefly present the beneficial effects of a healthy life style on ECs dysfunction.

7.1. Physical Activity. A large body of works has shown that moderate-intensity aerobic exercise training improves endothelial function in animals and humans with and without cardiovascular risk factors [247-251]. The multiple benefits of physical activity on survival and the harmful effects of a sedentary lifestyle made it a therapeutic modality potentially useful to treat patients with cardiovascular diseases. Its benefits regarding functional capacity can be explained by effects on endothelial properties and peripheral vascular resistance [252]. Exercise training reduces inflammation and an improvement in EC health could be a primary reason for the improvement in chronic inflammation [247].

Many studies have demonstrated evidence of abnormal endothelial function among patients with heart failure, which can be mitigated by exercise training [249]. Chronic heart failure is associated with increased levels of tumour necrosis factor- $\alpha$ and markers of endothelial damage, including ICAM-1 and E-selectin. Whereas acute bouts of exercise lead to an increase in proinflammatory cytokines and markers of endothelial damage, these effects were not seen when exercise was performed chronically in chronic heart failure patients $[250,251]$. Ten weeks of moderate intensity exercise training improved coronary arteriolar endothelial function and reduced tumour necrosis factor- $\alpha$ at heart level of type 2 diabetic mice [252]. It is interesting to note that diet plus exercise training may exert remarkable benefits when either diet or exercise alone could not demonstrate so evident benefits [251].

We believe that further investigations in this exciting field would facilitate the development of physical exercise and dietary supplements as adjunctive therapies in the management of cardiovascular diseases.
7.2. Diet. Numerous studies have shown that the acute administration of a high fat diet induces a transitory disruption of endothelial function. This effect has been observed with different types of fats, including saturated, monounsaturated (MUFA), and trans fatty acids [243, 253]. It has been estimated that over $2 \%$ of total calorie intake in the developed world comes from foods containing trans fatty acids [254]. Fatty acids, produced industrially by partial hydrogenation of vegetable oils, are present in semisolid fats used in the manufacture of margarine, pastry products, frozen foods, and others. Trans fatty acids are proinflammatory factors and induce endothelial dysfunction $[255,256]$, which may explain the relationship between their consumption and the risk of ischemic heart disease, sudden death, and possibly diabetes [257, 258].

It has been found that Mediterranean diet, characterized by a low content of saturated fats, reduces endothelial dysfunction and markers of vascular inflammation in patients with the metabolic syndrome $[259,260]$, as well as reducing insulin resistance [256, 261]. de Lorgeril et al. [262] confirmed that the benefits of the Mediterranean diet, in patients recovering from myocardial infarction, are due not only to its low saturated fat and linoleic acid content, but also to the quantities of vegetables and oleic and $\alpha$-linolenic acid, both found in olive oil. One possible explanation of the effects of unsaturated fatty acids is that they decrease ICAM expression, which would reduce leukocyte adhesion to dysfunctional endothelium [263]. However, in a study on a hundred patients with ischemic heart disease it was shown that a Mediterranean diet for one year did not change inflammatory or metabolic (cholesterol and triglycerides) biomarkers [256, 264]. Ong et al. [265] showed that also a diet rich in MUFA produces impairment in endothelial function when compared to a carbohydrate-rich meal. Similarly, it was observed that a diet rich in olive oil produces the same decline in flow-mediated vasodilatation as did a fast food meal $[243,253]$. Lowering saturated fat intake significantly reduced atherosclerosis progression and ICAM-1 levels after two years $[256,263]$. Polyunsaturated fatty acids (PUFA) appear to protect the endothelium through various mechanisms: inhibiting 
expression of VCAM-1 and inducing NO synthesis [256, 266]. However, it is important to remember that slimming diets low in carbohydrates and high in protein [267] or fats [268] or low in fats and high in carbohydrates [269] may reduce weight and improve lipid profile, potentially reducing atherosclerosis and risk for coronary heart disease, but they also have significant drawbacks such as ketosis, nutritional imbalances, significant renal and liver damage, and also atherosclerotic coronary disease and obesity [256, 270, 271]. The potential atheroprotective role of Mediterranean diet during the atherogenetic process is represented in Figure 7.

Several randomized trials have shown a beneficial effect of consuming the Mediterranean diet on markers of endothelial function [258, 272, 273]. A randomized crossover study of Marin and colleagues [274] in 20 Italian elderly people evaluated the effect of a Mediterranean diet on circulating endothelial microparticles and EPCs. Activated endothelial microparticles are complex vesicular structures shed from activated or apoptotic ECs and play a remarkable role in coagulation, inflammation, and angiogenesis contributing to the progression of vascular diseases; in particular activated endothelial microparticles are released in response to the damage of the vascular endothelium, whereas EPCs are involved in the maintenance and replacement of ECs. After 2 weeks, the Mediterranean diet lowered plasma concentrations of total activated and apoptotic EMPs and increased concentrations of EPCs as compared with a high saturated fat or low-fat diet. These results suggest and confirm that the Mediterranean diet may have beneficial effects on endothelial function and so cardiovascular diseases [272].

Ingestion of high levels of saturated fat [273] appear to cause rapid alterations in endothelial function, including reduced vasodilatation. Conversely, the vasodilation induced by a low-fat high carbohydrate diet could be attributable to increased production of NO by the endothelium [256, 275]. A study of Pérez-Jiménez et al. [276] showed that the Mediterranean diet for 28 days to healthy subjects produces a decrease in plasma markers of endothelial activation, suggesting a consequent improvement in endothelial function. Similarly, the chronic consumption of low-fat diets and Mediterranean diets was observed to improve endothelial function compared to a high-fat western diet [243, 277]. Leighton et al. [278] evaluated the effects of two high fat diets: MUFA and PUFA, both of these diets contain exiguous fruits and vegetables and were administered to healthy male during 3 weeks. It was detected that both diets, independent of the type of fat, elicited a significant decline in endothelial-dependent vasodilatation. This negative effect was reverted when the subjects added two glasses of red wine per day or fruit and vegetables to their diet, suggesting that high-fat diets induce EC dysfunction that can be counteracted with the consumption of natural antioxidants so that a dietary pattern rich in fruit, vegetables, fish, and olive oil appears to have beneficial effects on endothelial functions.

7.2.1. Polyphenols. A large number of studies have investigated the role of dietary components such as polyphenols and antioxidants, proposing that diet may prevent endothelial dysfunction hence improving endothelial function [272]. Polyphenols are the most abundant antioxidants in human diet and are widespread constituents of fruits, vegetables, cereals, olive, legumes, chocolate, and beverages, such as tea, coffee, and wine $[279,280]$. It is important to underline that many dietary polyphenols possess both direct and indirect antioxidant activities. The term direct and indirect antioxidants was originally used by the Food and Drug Administration to distinguish nutrients that "trap and deactivate reactive oxygen molecules" (e.g., vitamin C, vitamin $\mathrm{E}, \beta$-carotene) from those that are "precursors of coenzymes that are involved in oxidative stress but do not have direct antioxidant activities" (e.g., zinc, selenium, riboflavin). Later, these terms were redefined by Dinkova-Kostova and Talalay [281] who described two types of small-molecule antioxidants that protect against cellular oxidative damage [282, 283]. Various studies indicate that polyphenols may induce the upregulation of endogenous antioxidant enzymes and cytoprotective proteins such as quinone oxidoreductase-1, SOD, glutathione S-transferase, glutathione peroxidase, and heme oxygenase-1 hence exerting also an indirect antioxidant effect in addition to direct radical scavenging $[283,284]$.

Despite their wide distribution, the health effects of dietary polyphenols have been attentively studied only in recent years and several studies, although not all, have found an inverse association between polyphenol consumption and cardiovascular disease mortality [285].

Moreover, flavonoids, many of which are polyphenolic compounds, are believed to be beneficial for the prevention and treatment of cardiovascular diseases mainly by decreasing oxidative stress and increasing vasodilatation [279, 286, 287]. More than 8.000 different flavonoids have been described and since they are prerogative of the kingdom of plants, they are part of human diet with a daily total intake amounting to $1 \mathrm{~g}$, which is higher than all other classes of phytochemicals and known dietary antioxidants. In fact, the daily intake of vitamin $\mathrm{C}$, vitamin $\mathrm{E}$, and $\beta$ carotene from food is estimated minor of $100 \mathrm{mg}$ [279]. A large number of human intervention studies have evaluated the beneficial effects of flavonoid intake and foods containing flavonoids on endothelial function. Morand et al. [288] investigated the acute and 4-week effects of orange juice and its major flavonoid, hesperidin, on microvascular reactivity in a crossover study in 24 healthy overweight men and observed that the intake of orange juice flavonoids may have acute beneficial effects on endothelium but it does not provide evidence for a long-term administration. Moreover, epidemiological studies have suggested that regular moderate consumption of red wine, rich in flavonoids, is associated with increased NO expression hence the positive modulation of vascular tone and that consumption of cacao and green tea improved endothelial functions and this effect appears to be at least partly mediated by flavonoid components, like catechins.

Similarly, another study suggested that short- and longterm black tea consumption reverses endothelial dysfunction in patients with coronary heart disease $[243,289]$. 


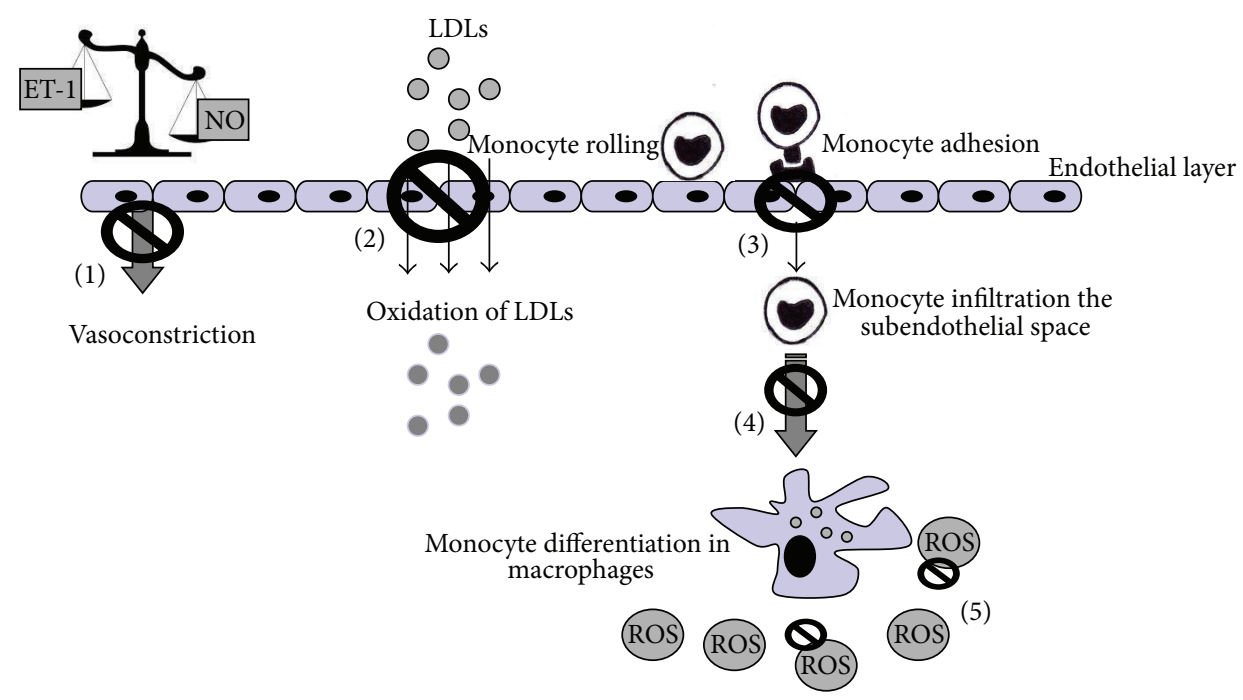

Figure 7: Potential atheroprotective role of Mediterranean diet during the atherogenetic process. The Mediterranean diet, with mainly its antioxidant properties, may (1) inhibit/reduce the imbalance between vasoconstrictors and vasodilators, (2) block oxidation of low density lipoproteins, (3) inhibit monocytes adhesion to endothelial cells constraining monocytes infiltration in the subendothelial space, (4) repress differentiation of macrophages in lipid-laden macrophages, defined as foam cells, and (5) reduce radical oxygen species syntheses. ET-1: endothelin-1; LDLs: low density lipoproteins; NO: nitric oxide; ROS: radical oxygen species.

For other foods such as citrus fruit and apples, the evidence for beneficial effects on endothelial function is currently under consideration.

The main problem in studing the beneficial effects of foods is judging whether the effect comes from specific compounds or from other bioactive compounds of these foods. Only a few intervention studies have been conducted with pure compounds, so it is important to take into account the possible synergistic effects of multiple dietary components that are part of a dietary pattern and so simulate better the reality of human lifestyle.

In the following paragraphs, we briefly describe the beneficial effects on the endothelium of two of the main food components of the Mediterranean diet, olive oil and red wine, and of some of the principal antioxidant supplementation actually studied [243].

7.2.2. Olive Oil. Olive oil is the main fat in the Mediterranean diet. The wide range of antiatherogenic effects associated with olive oil consumption could contribute to explain the low rate of cardiovascular mortality found in southern European Mediterranean countries, in comparison with other western countries, despite a high prevalence of coronary heart disease factors [290]. Olive oil, particularly a virgin olive oil rich diet, decreases prothrombotic environment, modifies platelet adhesion, coagulation, and fibrinolysis, and may improve endothelial function [290, 291]. The healthful properties of olive oil have been often attributed to its high content of MUFA, namely, oleic acid [292], but it is becoming clear that the content of oleic acid alone cannot fully explain the impact of olive oil on health. It should be underlined that olive oil, unlike other vegetable oils, contains high amounts of several micronutrient constituents, including polyphenolic compounds (100-1000 mg/kg) [293]. Around $80 \%$ or more of the olive oil phenolic compounds are lost in the refination process; thus, their content is higher in virgin olive oil than in other olive oils.

The cardioprotective effects of olive oil have been ascribed to its content of MUFA and the presence of other biologically minor constituents like polyphenols, tocopherols, and triterpenoids [260, 294, 295]. Among these compounds, tocopherols and phenolic compounds have demonstrated antioxidant properties that may improve endothelial function by reducing levels of ROS in the endothelium and, consequently, the production of endothelial adhesion molecules. Moreover, extra virgin olive oil through its phenolic compounds may increase glutathione reductase and glutathione peroxidase activities [296, 297].

At this regard, some findings suggest that both major and minor olive oil components may modulate inflammation and endothelial activation. In cultured ECs, oleic acid inhibited the expression of VCAM-1 mRNA levels, monocyte adhesion, and NF- $\kappa$ B $[298,299]$. In animal models, a diet rich in olive oil suppressed natural killer cell activity and the expression of receptors for interleukins [300, 301]. Isolated human LDL enriched in oleic acid reduced monocyte chemotaxis and adhesion, compared with linoleic-enriched LDL when being exposed to oxidative stress [290, 302]. Phytosterols and triterpenoids have anti-inflammatory and vasodilatation effects, respectively, but their roles in the endothelium need to be further studied. The increasing investigations on the properties of these minor compounds of olive oil may help to explain not only some of the classic beneficial effects of the Mediterranean diet, but also the emergence of other olivederived oils, such as pomace olive oil, which, being enriched with these minor components, might be helpful in preventing cardiovascular diseases [291]. 
Olive oil rich Mediterranean diet has been observed to improve the endothelium-dependent dilatation in hypercholesterolemic males [277, 290] and metabolic syndrome patients [261]. Ryan et al. [261] showed that an olive oil diet attenuates the endothelial dysfunction present during the consumption of a baseline diet high in PUFA. Moreover, Ruano et al. [303] reported that a meal containing highphenolic virgin olive oil improves the endothelial-dependent vasodilatation during postprandial state more than when the meal was taken with a similar olive oil, but with low-phenolic content.

Olive oil minor components have also been involved in the antioxidant activity of olive oil. Some components of the unsaponifiable fraction, such as squalene, $\beta$-sitosterol or triterpenes, have been shown to display antioxidant and chemopreventive activities and capacity to improve endothelial function decreasing the expression of cell adhesion molecules and increasing vasorelaxation [304].

The mechanisms by which olive oil and its components exert beneficial effects merit further investigation and further studies are required to obtain evidence of the benefits of olive oil consumption on primary end points for cardiovascular disease.

7.2.3. Red Wine. Wine has been part of the human culture for more than 3000 years, serving dietary and socioreligious functions [305]. Several prospective studies have consistently demonstrated that weak/moderate red wine consumption (one to two drinks per day) is strongly associated with a lower incidence of cardiovascular diseases compared with teetotal or occasional alcohol consumption. The cardiovascular benefits of wine are likely due to combined, additive, or perhaps synergistic effects of alcohol and other wine components (mainly resveratrol and other polyphenolic compounds) on atherogenesis, coagulation, and fibrinolysis $[305,306]$. Improved vascular function was shown in several experimental models of human diseases after administration of either red wine or its constituents and it was observed that the mechanisms involved in beneficial effects of natural polyphenols include also a reduction of platelet aggregation [307], increased high density lipoprotein (HDL) concentration [308], reduced LDL oxidation and concentration [307, $309,310]$, and improvement of antioxidant defence system $[311,312]$. Besides antioxidant properties, which play a significant role in cardioprotection, red wine polyphenols affect vascular function via modulation of NO bioavailability [313, 314]. Red wine compounds prevented metabolic and cardiovascular alterations in obese rats [310], improved endothelialmediated dilatation and plasma NO level in hypercholesterolemic rabbits $[307,315]$, and restored endothelial function in deoxycorticosterone acetate-salt hypertensive rats [316]. In rats with fully developed NO-deficient hypertension, administration of red wine compounds produced a greater blood pressure decrease and improved endothelial functions [307].

Resveratrol, natural polyphenol found in grapes and grape products, including wine, as well as other sources [317], also decreased the gene expression of the potent vasoconstrictor ET-1 [305, 318]. Corder et al. [319] showed that red wine is capable of reducing ET-1 synthesis leading again to enhanced vasodilation. Our research group observed that treatment with resveratrol of type I diabetic rats may induce increase in adiponectin, the main adipokine secreted by fat deposits, that is strictly associated with a significant decrease in circulating ECs and EC fragmentations and a significant increase in PECAM-1 positive cells; moreover, we observed that resveratrol treatment may decrease ICAM-1 and VCAM-1 and caspase- 3 activity in ECs, while increasing eNOS activity [320].

In humans, red wine and red wine compounds reduced blood pressure and improved forearm endothelial functions and NO production in young healthy individuals [321]. Similarly, a decrease of blood pressure in association with elevation of plasma NO was observed after both red wine and red wine compounds consumption in men at high cardiovascular risk [307, 322]. Additionally, treatment with red wine was found to reduce the susceptibility of LDLs to oxidation and to improve endothelium-dependent vasodilatation in patients with coronary heart disease [307, 323]. On the other hand, Andrade et al. [324] observed increased endothelial-mediated dilatation after short-term red wine consumption only in hypercholesterolemic, but not in hypertensive or healthy subjects [307]. However, in a study comparing the effect of water, red wine, beer, and vodka in healthy young subjects Huang et al. [325] found that only red wine affected endothelial function and significantly increased plasma levels of NO. Moreover, it is important to remember that, regarding the biological mechanisms linking endothelial function to moderate wine intake, it has been reported that alcohol per se can induce a marked increase in NO synthesis in primary cultures of bovine aortic ECs and human umbilical ECs, sustained by a rapid increase of eNOS protein and mRNA expression levels. In particular, both eNOS protein and mRNA increase by nearly twofold within 3 hours and gradually decline after $0.1 \%$ ethanol ingestion, but the increased levels of mRNA persist up to 24 hours $[305,326]$. A 20-hour treatment of human umbilical vein ECs with an alcohol-free red wine polyphenol extract also led to a concentration-dependent increase in NO release, associated with an up to twofold increase of human eNOS promoter activity. Remarkably, although polyphenol extracts from wines of specific origin and grape cultivars vary strongly in their individual activity, when averaged, the activity cannot be attributed to a specific grape cultivar or growing area [305, 327]. Cuevas and colleagues [328] observed that moderate red wine consumption counteracts endothelial dysfunction induced by a high fat western diet administered to healthy men. The effects of ethanol and polyphenols on NO and consequently on endothelial function are very important, since endothelial function is an early indicator of atherosclerosis and vessel damage [316, 329, 330]. Moderate red wine consumption improved neovascularization and blood flow recovery after ischemia in hypercholesterolemic mice and had a positive effect on EPCs number and functional activity [331, 332]. Huang et al. [325] reported that red wine consumption by healthy subjects enhanced circulating EPC levels and improved EPC 
functions by modifying NO bioavailability. These studies support a modulatory effect of ethanol and/or polyphenols on EPC that may be antiatherogenic. Moreover, in a single blind crossover study, Whelan et al. [333] reported that the consumption of $4 \mathrm{~mL} / \mathrm{kg}$ of either red or white wine with a light meal acutely improved brachial endothelial-mediated dilatation after 6 hours, whereas blood-alcohol levels had returned to baseline values by this time; the magnitude of this effect on endothelial function was substantially similar after both red and white wines. In healthy subjects, ingestion of 250 to $500 \mathrm{~mL}$ of red wine or dealcoholized red wine increased, in some, but not all studies, flow-mediated vasodilatation as assessed in the brachial artery by plethysmography [334336].

It is still unclear whether the beneficial effects of red wine intake can be attributed to any specific type of grape and therefore any single wine source cannot be considered better than any other and it remains to be determined whether the reported benefits of red wine are based on one or more socioeconomic confounders. Accordingly, the beneficial effects of red wine intake in human health should be better defined and additional research works are required before any firm recommendation can be made to abstainers to initiate a light to moderate consumption of red wine [305]. Therefore, until more studies are conducted in order to elucidate this matter, it is not safe to advise consumption of a glass of red wine, as it is not clear if it would benefit or harm endothelial function in the immediate postprandial state [314].

\subsubsection{Antioxidants Supplementation}

Tempol. Due to the central role of oxidative stress in development of cardiovascular diseases, many studies have been conducted over the past 20 years to investigate the potential use of antioxidants or mimetic of endogenous antioxidants, such as vitamins $\mathrm{C}$ and $\mathrm{E}$, to reduce cardiovascular alterations [272].

Administration of tempol, a cell permeable SOD mimetic, has shown improvements in diabetes associated microvascular complications, such as nephropathy and retinopathy $[59,337]$. In addition, tempol restores endothelial vasodilatation in large conduit vessels of alloxan-induced diabetic rabbits $[58,336]$. Tempol increases endothelium-dependent vasodilatation in arteries from hypertensive animals, most likely through a lowering of ROS, but other mechanisms also appear to contribute to the effect [295].

MN40403, another highly specific nonpeptide SOD mimetic, was able to reverse endothelial dysfunction ex vivo by targeting NADPH oxidase-mediated superoxide production at aorta level of apolipoprotein E-deficient mice [58, 338].

Vitamins $C$ and $E$. It has been detected that vitamins C and vitamin $\mathrm{E}$, water, and lipid soluble antioxidants, respectively, produce beneficial effects on endothelial functions by modulating the downregulation of eNOS expression [339]. Moreover, the deleterious effects of postprandial hypertriglyceridemia on endothelial-dependent vasodilation can be counteracted by the simultaneous administration of vitamins C and E [243, 340, 341]. Maio et al. [342] investigated the acute effects of arterial vitamin $\mathrm{C}$ infusion on forearm blood flow in response to acetylcholine (a NO-dependent vasodilator) in 190 dipper and nondipper hypertensive patients (in dipper patients, but not in nondipper patients, blood pressure drops during night period). The authors found that vitamin $\mathrm{C}$ treatment improved blood flow following acetylcholine administration in both nondipper and dipper patients, but particularly in dipper ones. This observation supports and confirms the hypothesis that vitamin $\mathrm{C}$ improves endothelial function in hypertensive patients with impaired NO physiology. Vitamin C intake has also been shown to increase muscular blood flow during exercise in older adults and this effect is associated with improved endothelium-dependent vasodilatation mainly due to increased $\mathrm{NO}$ availability via eNOS [272, 343, 344].

The antioxidant effects of vitamins $\mathrm{C}$ and $\mathrm{E}$ are well established. However, studies both in vitro $[345,346]$ and in vivo $[347,348]$ have shown that antioxidant vitamins, particularly vitamin $\mathrm{E}$, can have a paradoxical prooxidant effect when administrated under conditions of normal or low basal oxidative stress [349]. Indeed, the general trend towards increased cardiovascular mortality has opened a serious debate about the safety of vitamin E supplementation in high risk individuals. Further evidence about the efficacy of antioxidant vitamins is awaited from other ongoing trials of vitamin $\mathrm{E}$ alone or in combination with other antioxidants. Trying to explain the failure of vitamin E, it has been suggested that antioxidant therapy may require a longer treatment period because its primary mechanism of action is the prevention of new lesion formation [350].

Melatonin. Melatonin, an endogenously produced indoleamine, is a remarkably functionally pleiotropic molecule [351] which functions as a highly effective antioxidant and free radical scavenger [352, 353]. Endogenously produced and exogenously administered melatonin has known beneficial actions on the cardiovascular system [354, 355]. In particular, the antioxidant action of melatonin and its possible interaction with EDHF may contribute to blood pressure lowering effect, which was observed even when the NO pathway was inhibited [356]. However, melatonin seems to increase NO levels either through the stimulation of NO production and/or the prevention of coupling to the superoxide anion radical [357]. In addition melatonin was able to modulate in vitro acetylcholine-induced relaxation or phenylephrine-induced vasoconstriction of aortic rings of aging rats $[358,359]$ and New Zealand rabbits, respectively, in an endothelium-dependent manner [360]. Nevertheless, the mechanisms of these antihypertensive effects of melatonin are actually not completely understood.

Melatonin also may inhibit endothelium-derived adhesion molecules formation, reduce fatty acids infiltration in the intimal layer [361], and neutralize free radicals [362, 363]. Moreover, melatonin was demonstrated to prevent tissue injury and structural and functional alterations in the vasculature induced by cigarette smoking. Our research group observed and confirmed that melatonin minimized 
the damage induced by nicotine, reestablished the physiological balance between vasodilatation (increasing eNOS) and vasoconstriction (decreasing ET-1), induced antioxidant enzymes, and downregulated adhesive molecules on ECs [46, 220, 221].

\section{Conclusions}

Actually, compelling evidences indicate that an increased consumption of correct diet containing nutritive and nonnutritive compounds may contribute to the improvement of the quality of life by delaying onset and reducing the risk of cardiovascular diseases and, in particular, the development of endothelial dysfunction. In this context, wine, tea, fruits, vegetables, and olive oil received much attention, because they are particularly rich in natural antioxidants.

However, a better understanding of the mechanism(s) underlying EC dysfunction during cardiovascular physiopathology is a prerequisite for effective pharmacological and nonpharmacological interventions and treatments.

In conclusion, the proposal that antioxidants may ameliorate endothelial dysfunction is very interesting and promising, but further studies are needed to better understand the mechanisms that underline the biological effect of healthy life style.

\section{Conflict of Interests}

The authors declare that there is no conflict of interests regarding the publication of this paper.

\section{Authors' Contribution}

Rita Rezzani and Luigi Fabrizio Rodella equally contributed to this paper.

\section{Acknowledgments}

The authors are sincerely thankful to Mrs. Lorena Giugno for her editing support.

\section{References}

[1] T. Gori, S. Dragoni, G. di Stolfo, and S. Forconi, "Endothelium and haemorheology," Annali dell'Istituto Superiore di Sanita, vol. 43, no. 2, pp. 124-129, 2007.

[2] T. Minami and W. C. Aird, "Endothelial cell gene regulation," Trends in Cardiovascular Medicine, vol. 15, no. 5, pp. 174-184, 2005.

[3] W. C. Aird, "Phenotypic heterogeneity of the endothelium: I. Structure, function, and mechanisms," Circulation Research, vol. 100, no. 2, pp. 158-173, 2007.

[4] E. R. Weibel and G. E. Palade, "New cytoplasmic components in arterial endothelia," The Journal of Cell Biology, vol. 23, pp. 101-112, 1964.

[5] W. C. Aird, "Phenotypic heterogeneity of the endothelium: II. Representative vascular beds," Circulation Research, vol. 100, no. 2, pp. 174-190, 2007.
[6] K. Yano, D. Gale, S. Massberg et al., "Phenotypic heterogeneity is an evolutionarily conserved feature of the endothelium," Blood, vol. 109, no. 2, pp. 613-615, 2007.

[7] W. C. Aird, "Endothelium in health and disease," Pharmacological Reports, vol. 60, no. 1, pp. 139-143, 2008.

[8] H. F. Galley and N. R. Webster, "Physiology of the endothelium," British Journal of Anaesthesia, vol. 93, no. 1, pp. 105-113, 2004.

[9] H. G. Augustin, D. H. Kozian, and R. C. Johnson, "Differentiation of endothelial cells: analysis of the constitutive and activated endothelial cell phenotypes," BioEssays, vol. 16, no. 12, pp. 901-906, 1994.

[10] D. B. Cines, E. S. Pollak, C. A. Buck et al., "Endothelial cells in physiology and in the pathophysiology of vascular disorders," Blood, vol. 91, no. 10, pp. 3527-3561, 1998.

[11] J.-P. Girard and T. A. Springer, "High Endothelial Venules (HEVs): specialized endothelium for lymphocyte migration," Immunology Today, vol. 16, no. 9, pp. 449-457, 1995.

[12] M. Miyasaka and T. Tanaka, "Lymphocyte trafficking across high endothelial venules: dogmas and enigmas," Nature Reviews Immunology, vol. 4, no. 5, pp. 360-370, 2004.

[13] F. Florey, “The endothelial cell," British Medical Journal, vol. 2, no. 5512, pp. 487-490, 1966.

[14] E. Wisse, "An electron microscopic study of the fenestrated endothelial lining of rat liver sinusoids," Journal of Ultrasructure Research, vol. 31, no. 1-2, pp. 125-150, 1970.

[15] M. Simionescu, N. Simionescu, and G. E. Palade, "Morphometric data on the endothelium of blood capillaries," The Journal of Cell Biology, vol. 60, no. 1, pp. 128-152, 1974.

[16] A. Caggiati, M. Phillips, A. Lametschwandtner, and C. Allegra, "Valves in small veins and venules," European Journal of Vascular and Endovascular Surgery, vol. 32, no. 4, pp. 447-452, 2006.

[17] D. Feng, J. A. Nagy, H. F. Dvorak, and A. M. Dvorak, "Ultrastructural studies define soluble macromolecular, particulate, and cellular transendothelial cell pathways in venules, lymphatic vessels, and tumor-associated microvessels in man and animals," Microscopy Research and Technique, vol. 57, no. 5, pp. 289-326, 2002

[18] P. S. Frenette, R. C. Johnson, R. O. Hynes, and D. D. Wagner, "Platelets roll on stimulated endothelium in vivo: an interaction mediated by endothelial P-selectin," Proceedings of the National Academy of Sciences of the United States of America, vol. 92, no. 16, pp. 7450-7454, 1995.

[19] M. Mori, J. W. Salter, T. Vowinkel, C. F. Krieglstein, K. Y. Stokes, and D. N. Granger, "Molecular determinants of the prothrombogenic phenotype assumed by inflamed colonic venules," American Journal of Physiology, vol. 288, no. 5, pp. G920-G926, 2005.

[20] A. Tailor and D. N. Granger, "Hypercholesterolemia promotes leukocyte-dependent platelet adhesion in murine postcapillary venules," Microcirculation, vol. 11, no. 7, pp. 597-603, 2004.

[21] D. Cooper, J. Russell, K. D. Chitman, M. C. Williams, R. E. Wolf, and D. N. Granger, "Leukocyte dependence of platelet adhesion in postcapillary venules," American Journal of Physiology, vol. 286, no. 5, pp. H1895-H1900, 2004.

[22] G. Kraal and R. E. Mebius, "High endothelial venules: lymphocyte traffic control and controlled traffic," Advances in Immunology, vol. 65, pp. 347-395, 1997.

[23] U. H. von Andrian and T. R. Mempel, "Homing and cellular traffic in lymph nodes," Nature Reviews Immunology, vol. 3, no. 11, pp. 867-878, 2003. 
[24] P. R. Streeter, B. T. Rouse, and E. C. Butcher, "Immunohistologic and functional characterization of a vascular addressin involved in lymphocyte homing into peripheral lymph nodes," The Journal of Cell Biology, vol. 107, no. 5, pp. 1853-1862, 1988.

[25] A. O. Anderson and S. Shaw, "T cell adhesion to endothelium: the FRC conduit system and other anatomic and molecular features which facilitate the adhesion cascade in lymph node," Seminars in Immunology, vol. 5, no. 4, pp. 271-282, 1993.

[26] D. L. Brutsaert, "Cardiac endothelial-myocardial signaling: its role in cardiac growth, contractile performance, and rhythmicity," Physiological Reviews, vol. 83, no. 1, pp. 59-115, 2003.

[27] D. A. Narmoneva, R. Vukmirovic, M. E. Davis, R. D. Kamm, and R. T. Lee, "Endothelial cells promote cardiac myocyte survival and spatial reorganization: implications for cardiac regeneration," Circulation, vol. 110, no. 8, pp. 962-968, 2004.

[28] K. Yamamoto, V. de Waard, C. Fearns, and D. J. Loskutoff, “Tissue distribution and regulation of murine von Willebrand factor gene expression in vivo," Blood, vol. 92, no. 8, pp. 2791-2801, 1998.

[29] H. Cai, Z. Li, A. Goette et al., "Downregulation of endocardial nitric oxide synthase expression and nitric oxide production in atrial fibrillation: potential mechanisms for atrial thrombosis and stroke," Circulation, vol. 106, no. 22, pp. 2854-2858, 2002.

[30] L. J. Andries, D. L. Brutsaert, and S. U. Sys, "Nonuniformity of endothelial constitutive nitric oxide synthase distribution in cardiac endothelium," Circulation Research, vol. 82, no. 2, pp. 195-203, 1998.

[31] J. Bischoff and E. Aikawa, "Progenitor cells confer plasticity to cardiac valve endothelium," Journal of Cardiovascular Translational Research, vol. 4, no. 6, pp. 710-719, 2011.

[32] R. J. Esper, R. A. Nordaby, J. O. Vilariño, A. Paragano, J. L. Cacharrón, and R. A. Machado, "Endothelial dysfunction: a comprehensive appraisal," Cardiovascular Diabetology, vol. 5, article 4, 2006.

[33] E. Dejana, M. Corada, and M. G. Lampugnani, "Endothelial cell-to-cell junctions," FASEB Journal, vol. 9, no. 10, pp. 910-918, 1995.

[34] K. A. Pasyk and B. A. Jakobczak, "Vascular endothelium: recent advances," European Journal of Dermatology, vol. 14, no. 4, pp. 209-213, 2004.

[35] A. G. Passerini, D. C. Polacek, C. Shi et al., "Coexisting proinflammatory and antioxidative endothelial transcription profiles in a disturbed flow region of the adult porcine aorta," Proceedings of the National Academy of Sciences of the United States of America, vol. 101, no. 8, pp. 2482-2487, 2004.

[36] C. Lupu, A. D. Westmuckett, G. Peer et al., "Tissue factordependent coagulation is preferentially up-regulated within arterial branching areas in a baboon model of Escherichia coli sepsis," American Journal of Pathology, vol. 167, no. 4, pp. 11611172, 2005.

[37] M. P. Bevilacqua, J. S. Pober, D. L. Mendrick, R. S. Cotran, and M. A. Gimbrone Jr., "Identification of an inducible endothelialleukocyte adhesion molecule," Proceedings of the National Academy of Sciences of the United States of America, vol. 84, no. 24, pp. 9238-9242, 1987.

[38] M. P. Bevilacqua, S. Stengelin, M. A. Gimbrone Jr., and B. Seed, "Endothelial leukocyte adhesion molecule 1: an inducible receptor for neutrophils related to complement regulatory proteins and lectins," Science, vol. 243, no. 4895, pp. 1160-1165, 1989.

[39] M. Uematsu, Y. Ohara, J. P. Navas et al., "Regulation of endothelial cell nitric oxide synthase mRNA expression by shear stress," American Journal of Physiology, vol. 269, no. 6, part 1, pp. C1371-C1378, 1995.

[40] S. Verma, M. R. Buchanan, and T. J. Anderson, "Endothelial function testing as a biomarker of vascular disease," Circulation, vol. 108, no. 17, pp. 2054-2059, 2003.

[41] M. Yanagisawa, A. Inoue, T. Ishikawa et al., "Primary structure, synthesis, and biological activity of rat endothelin, an endothelium-derived vasoconstrictor peptide," Proceedings of the National Academy of Sciences of the United States of America, vol. 85, no. 18, pp. 6964-6967, 1988.

[42] J. W. Butany, S. Verma, R. L. Leask, B. Mohsen, and S. L. Asa, "Genetic abnormalities of the endothelium," Microscopy Research and Technique, vol. 60, no. 1, pp. 30-37, 2003.

[43] E. Thorin and D. J. Webb, "Endothelium-derived endothelin-1," Pflugers Archiv, vol. 459, no. 6, pp. 951-958, 2010.

[44] R. Rezzani, L. Rodella, and R. Bianchi, "Induction of endothelin in rat kidney after cyclosporine A treatment," Acta Histochemica, vol. 103, no. 4, pp. 423-431, 2001.

[45] R. Rezzani, L. Rodella, B. Buffoli et al., "Change in renal heme oxygenase expression in cyclosporine A-induced injury," Journal of Histochemistry and Cytochemistry, vol. 53, no. 1, pp. 105-112, 2005.

[46] L. F. Rodella, F. Filippini, F. Bonomini, R. Bresciani, R. J. Reiter, and R. Rezzani, "Beneficial effects of melatonin on nicotineinduced vasculopathy," Journal of Pineal Research, vol. 48, no. 2, pp. 126-132, 2010.

[47] L. F. Rodella, G. Favero, C. Rossini et al., "Aging and vascular dysfunction: beneficial melatonin effects," Age, vol. 35, no. 1, pp. 103-115, 2013.

[48] M.-E. Lee, K. D. Bloch, J. A. Clifford, and T. Quertermous, "Functional analysis of the endothelin-1 gene promoter. Evidence for an endothelial cell-specific cis-acting sequence," Journal of Biological Chemistry, vol. 265, no. 18, pp. 1044610450, 1990.

[49] G. P. Rossi, A. Sacchetto, M. Cesari, and A. C. Pessina, "Interactions between endothelin-1 and the renin-angiotensin-aldosterone system," Cardiovascular Research, vol. 43, no. 2, pp. 300307, 1999.

[50] G. P. Rossi, A. Sacchetto, D. Rizzoni et al., "Blockade of angiotensin II type 1 receptor and not of endothelin receptor prevents hypertension and cardiovascular disease in transgenic (mREN2)27 rats via adrenocortical steroid-independent mechanisms," Arteriosclerosis, Thrombosis, and Vascular Biology, vol. 20, no. 4, pp. 949-956, 2000.

[51] A. W. Hahn, T. J. Resink, T. Scott-Burden, J. Powell, Y. Dohi, and F. R. Bühler, "Stimulation of endothelin mRNA and secretion in rat vascular smooth muscle cells: a novel autocrine function," Cell Regulation, vol. 1, no. 9, pp. 649-659, 1990.

[52] C.-P. Sung, A. J. Arleth, B. L. Storer, and E. H. Ohlstein, "Angiotensin type 1 receptors mediate smooth muscle proliferation and endothelin biosynthesis in rat vascular smooth muscle," Journal of Pharmacology and Experimental Therapeutics, vol. 271, no. 1, pp. 429-437, 1994.

[53] H. Ito, Y. Hirata, S. Adachi et al., "Endothelin-1 is an autocrine/ paracrine factor in the mechanism of angiotensin II-induced hypertrophy in cultured rat cardiomyocytes," Journal of Clinical Investigation, vol. 92, no. 1, pp. 398-403, 1993.

[54] P. Moreau, H. Takase, C. F. Küng, S. Shaw, and T. F. Lüscher, "Blood pressure and vascular effects of endothelin blockade in chronic nitric oxide-deficient hypertension," Hypertension, vol. 29, no. 3, pp. 763-769, 1997. 
[55] R. P. McEver, J. H. Beckstead, K. L. Moore, L. MarshallCarlson, and D. F. Bainton, "GMP-140, a platelet $\alpha$-granule membrane protein, is also synthesized by vascular endothelial cells and is localized in Weibel-Palade bodies," Journal of Clinical Investigation, vol. 84, no. 1, pp. 92-99, 1989.

[56] K. Iiyama, L. Hajra, M. Iiyama et al., "Patterns of vascular cell adhesion molecule- 1 and intercellular adhesion molecule- 1 expression in rabbit and mouse atherosclerotic lesions and at sites predisposed to lesion formation," Circulation Research, vol. 85, no. 2, pp. 199-207, 1999.

[57] M. D. Chávez, N. Lakshmanan, and M. Kavdia, "Impact of superoxide dismutase on nitric oxide and peroxynitrite levels in the microcirculation - a computational model," in Proceedings of the 29th Annual International Conference of IEEE Engineering in Medicine and Biology Society (EMBS '07), pp. 1022-1026, Lyon, France, August 2007.

[58] A. Sharma, P. N. Bernatchez, and J. B. de Haan, "Targeting endothelial dysfunction in vascular complications associated with diabetes," International Journal of Vascular Medicine, vol. 2012, Article ID 750126, 12 pages, 2012.

[59] C.-L. M. Cooke and S. T. Davidge, "Endothelial-dependent vasodilation is reduced in mesenteric arteries from superoxide dismutase knockout mice," Cardiovascular Research, vol. 60, no. 3, pp. 635-642, 2003.

[60] H. Goto, T. Nishikawa, K. Sonoda et al., "Endothelial MnSOD overexpression prevents retinal VEGF expression in diabetic mice," Biochemical and Biophysical Research Communications, vol. 366, no. 3, pp. 814-820, 2008.

[61] J. Contrino, G. Hair, D. L. Kreutzer, and F. R. Rickles, "In situ detection of tissue factor in vascular endothelial cells: correlation with the malignant phenotype of human breast disease," Nature Medicine, vol. 2, no. 2, pp. 209-215, 1996.

[62] J. Crawley, F. Lupu, A. D. Westmuckett, N. J. Severs, V. V. Kakkar, and C. Lupu, "Expression, localization, and activity of tissue factor pathway inhibitor in normal and athrosclerotic human vessels," Arteriosclerosis, Thrombosis, and Vascular Biology, vol. 20, no. 5, pp. 1362-1373, 2000.

[63] A. Solovey, R. Kollander, A. Shet et al., "Endothelial cell expression of tissue factor in sickle mice is augmented by hypoxia/ reoxygenation and inhibited by lovastatin," Blood, vol. 104, no. 3, pp. 840-846, 2004.

[64] T. Nagayasu, S. Saadi, R. A. Holzknecht, T. B. Plummer, and J. L. Platt, "Expression of tissue factor mRNA in cardiac xenografts: clues to the pathogenesis of acute vascular rejection," Transplantation, vol. 69, no. 4, pp. 475-482, 2000.

[65] E. Dejana, "Endothelial cell-cell junctions: happy together," Nature Reviews Molecular Cell Biology, vol. 5, no. 4, pp. 261-270, 2004.

[66] G. Bazzoni and E. Dejana, "Endothelial cell-to-cell junctions: molecular organization and role in vascular homeostasis," Physiological Reviews, vol. 84, no. 3, pp. 869-901, 2004.

[67] M. G. Farquhar and G. E. Palade, "Junctional complexes in various epithelia," The Journal of Cell Biology, vol. 17, pp. 375412, 1963.

[68] G. van Meer, B. Gumbiner, and K. Simons, "The tight junction does not allow lipid molecules to diffuse from one epithelial cell to the next," Nature, vol. 322, no. 6080, pp. 639-641, 1986.

[69] E. A. Runkle and D. Mu, "Tight junction proteins: from barrier to tumorigenesis," Cancer Letters, vol. 337, no. 1, pp. 41-48, 2013.

[70] G. Bazzoni, "The JAM family of junctional adhesion molecules," Current Opinion in Cell Biology, vol. 15, no. 5, pp. 525-530, 2003.
[71] K. Ebnet, "Organization of multiprotein complexes at cell-cell junctions," Histochemistry and Cell Biology, vol. 130, no. 1, pp. $1-20,2008$.

[72] J. D. Schulzke, D. Günzel, L. J. John, and M. Fromm, "Perspectives on tight junction research," Annals of the New York Academy of Sciences, vol. 1257, pp. 1-19, 2012.

[73] F. R. Curry and R. H. Adamson, "Tonic regulation of vascular permeability," Acta Physiologica, vol. 207, no. 4, pp. 628-649, 2013.

[74] E. Dejana and C. Giampietro, "Vascular endothelial-cadherin and vascular stability," Current Opinion in Hematology, vol. 19, no. 3, pp. 218-223, 2012.

[75] H. Drexler, A. M. Zeiher, K. Meinzer, and H. Just, "Correction of endothelial dysfunction in coronary microcirculation of hypercholesterolaemic patients by L-arginine," The Lancet, vol. 338, no. 8782-8783, pp. 1546-1550, 1991.

[76] J.-P. Gratton, P. Bernatchez, and W. C. Sessa, "Caveolae and caveolins in the cardiovascular system," Circulation Research, vol. 94, no. 11, pp. 1408-1417, 2004.

[77] C. J. Knowles, M. Dionne, M. Cebova, and I. M. Pinz, "Palmitate-induced translocation of caveolin-3 and endothelial nitric oxide synthase in cardiomyocytes," Online Journal of Biological Sciences, vol. 11, no. 2, pp. 27-36, 2011.

[78] G. Sowa, "Caveolae, caveolins, cavins, and endothelial cell function: new insights," Frontiers in Physiology, vol. 2, article 120, 2012

[79] G. García-Cardeña, P. Martasek, B. S. S. Masters et al., "Dissecting the interaction between Nitric Oxide Synthase (NOS) and caveolin. Functional significance of the nos caveolin binding domain in vivo," Journal of Biological Chemistry, vol. 272, no. 41, pp. 25437-25440, 1997.

[80] E. Sbaa, F. Frérart, and O. Feron, "The double regulation of endothelial nitric oxide synthase by caveolae and caveolin: a paradox solved through the study of angiogenesis," Trends in Cardiovascular Medicine, vol. 15, no. 5, pp. 157-162, 2005.

[81] J. Saliez, C. Bouzin, G. Rath et al., "Role of caveolar compartmentation in endothelium-derived hyperpolarizing factormediated relaxation- $\mathrm{ca}^{2+}$ signals and gap junction function are regulated by caveolin in endothelial cells," Circulation, vol. 117, no. 8, pp. 1065-1074, 2008.

[82] P. N. Bernatcher, P. M. Bauer, J. Yu, J. S. Prendergast, P. He, and W. C. Sessa, "Dissecting the molecular control of endothelial NO synthase by caveolin-1 using cell-permeable peptides," Proceedings of the National Academy of Sciences of the United States of America, vol. 102, no. 3, pp. 761-766, 2005.

[83] T. Murata, M. I. Lin, R. V. Stan, P. M. Bauer, J. Yu, and W. C. Sessa, "Genetic evidence supporting caveolae microdomain regulation of calcium entry in endothelial cells," Journal of Biological Chemistry, vol. 282, no. 22, pp. 16631-16643, 2007.

[84] T. Lockwich, B. B. Singh, X. Liu, and I. S. Ambudkar, "Stabilization of cortical actin induces internalization of Transient Receptor Potential 3 (Trp3)-associated caveolar $\mathrm{Ca}^{2+}$ signaling complex and loss of $\mathrm{Ca}^{2+}$ influx without disruption of Trp3inositol trisphosphate receptor association," Journal of Biological Chemistry, vol. 276, no. 45, pp. 42401-42408, 2001.

[85] M. T. Nelson, Y. H. Yu Huang, J. E. Brayden, J. Hescheler, and N. B. Standen, "Arterial dilations in response to calcitonin generelated peptide involve activation of $\mathrm{K}^{+}$channels," Nature, vol. 344, no. 6268, pp. 770-773, 1990.

[86] M. Félétou and P. M. Vanhoutte, "Endothelium-derived hyperpolarizing factor: where are we now?" Arteriosclerosis, Thrombosis, and Vascular Biology, vol. 26, no. 6, pp. 1215-1225, 2006. 
[87] J.-F. Jasmin, P. G. Frank, and M. P. Lisanti, Caveolins and Caveolae-Roles in Signaling and Disease Mechanisms, Springer, 2012.

[88] H. Chen, J. Yang, P. S. Low, and J.-X. Cheng, "Cholesterol level regulates endosome motility via Rab proteins," Biophysical Journal, vol. 94, no. 4, pp. 1508-1520, 2008.

[89] O. Feron and J.-L. Balligand, "Caveolins and the regulation of endothelial nitric oxide synthase in the heart," Cardiovascular Research, vol. 69, no. 4, pp. 788-797, 2006.

[90] G. Sowa, "Novel insights into the role of caveolin-2 in cell- and tissue-specific signaling and function," Biochemistry Research International, vol. 2011, Article ID 809259, 9 pages, 2011.

[91] D. J. Beech, "Characteristics of transient receptor potential canonical calcium-permeable channels and their relevance to vascular physiology and disease," Circulation Journal, vol. 77, no. 3, pp. 570-579, 2013.

[92] A. Dietrich, H. Kalwa, and T. Gudermann, "TRPC channels in vascular cell function," Thrombosis and Haemostasis, vol. 103, no. 2, pp. 262-270, 2010.

[93] M. Freichel, S. H. Suh, A. Pfeifer et al., "Lack of an endothelial store-operated $\mathrm{Ca}^{2+}$ current impairs agonist-dependent vasorelaxation in TRP4 $4^{-/-}$mice," Nature Cell Biology, vol. 3, no. 2, pp. 121-127, 2001.

[94] T. Yoshida, R. Inoue, T. Morii et al., "Nitric oxide activates TRP channels by cysteine S-nitrosylation," Nature Chemical Biology, vol. 2, no. 11, pp. 596-607, 2006.

[95] P. Chaudhuri, S. M. Colles, D. S. Damron, and L. M. Graham, "Lysophosphatidylcholine inhibits endothelial cell migration by increasing intracellular calcium and activating calpain," Arteriosclerosis, Thrombosis, and Vascular Biology, vol. 23, no. 2, pp. 218-223, 2003.

[96] H.-Y. Kwan, Y. Huang, and X. Yao, "Store-operated calcium entry in vascular endothelial cells is inhibited by cGMP via a protein kinase G-dependent mechanism," Journal of Biological Chemistry, vol. 275, no. 10, pp. 6758-6163, 2000.

[97] H.-Y. Kwan, Y. Huang, and X. Yao, "Regulation of canonical transient receptor potential isoform 3 (TRPC3) channel by protein kinase G," Proceedings of the National Academy of Sciences of the United States of America, vol. 101, no. 8, pp. 26252630, 2004.

[98] M. Poteser, A. Graziani, C. Rosker et al., "TRPC3 and TRPC4 associate to form a redox-sensitive cation channel: evidence for expression of native TRPC3-TRPC4 heteromeric channels in endothelial cells," Journal of Biological Chemistry, vol. 281, no. 19, pp. 13588-13595, 2006.

[99] B. A. Miller and W. Zhang, "TRP channels as mediators of oxidative stress," Advances in Experimental Medicine and Biology, vol. 704, pp. 531-544, 2011.

[100] M. Chen, T. Masaki, and T. Sawamura, "LOX-1, the receptor for oxidized low-density lipoprotein identified from endothelial cells: implications in endothelial dysfunction and atherosclerosis," Pharmacology and Therapeutics, vol. 95, no. 1, pp. 89-100, 2002.

[101] P. E. Szmitko, C.-H. Wang, R. D. Weisel, G. A. Jeffries, T. J. Anderson, and S. Verma, "Biomarkers of vascular disease linking inflammation to endothelial activation part II," Circulation, vol. 108, no. 17, pp. 2041-2048, 2003.

[102] I. Andreou, D. Tousoulis, C. Tentolouris, C. Antoniades, and C. Stefanadis, "Potential role of endothelial progenitor cells in the pathophysiology of heart failure: clinical implications and perspectives," Atherosclerosis, vol. 189, no. 2, pp. 247-254, 2006.
[103] C. P. Lin, F. Y. Lin, P. H. Huang et al., "Endothelial progenitor cell dysfunction in cardiovascular diseases: role of reactive oxygen species and inflammation," BioMed Research International, vol. 2013, Article ID 845037, 10 pages, 2013.

[104] A. Aicher, A. M. Zeiher, and S. Dimmeler, "Mobilizing endothelial progenitor cells," Hypertension, vol. 45, no. 3, pp. 321-325, 2005.

[105] H. Iwaguro, J.-I. Yamaguchi, C. Kalka et al., "Endothelial progenitor cell vascular endothelial growth factor gene transfer for vascular regeneration," Circulation, vol. 105, no. 6, pp. 732738, 2002.

[106] M. Peichev, A. J. Naiyer, D. Pereira et al., "Expression of VEGFR2 and $\mathrm{AC} 133$ by circulating human $\mathrm{CD}^{+} 4^{+}$cells identifies a population of functional endothelial precursors," Blood, vol. 95, no. 3, pp. 952-958, 2000.

[107] C. Urbich, A. I. de Souza, L. Rossig et al., "Proteomic characterization of human early pro-angiogenic cells," Journal of Molecular and Cellular Cardiology, vol. 50, no. 2, pp. 333-336, 2011.

[108] M. E. J. Reinders, T. J. Rabelink, and D. M. Briscoe, "Angiogenesis and endothelial cell repair in renal disease and allograft rejection," Journal of the American Society of Nephrology, vol. 17, no. 4, pp. 932-942, 2006.

[109] J. P. Kirton and Q. Xu, "Endothelial precursors in vascular repair," Microvascular Research, vol. 79, no. 3, pp. 193-199, 2010.

[110] M. Vasa, S. Fichtlscherer, A. Aicher et al., "Number and migratory activity of circulating endothelial progenitor cells inversely correlate with risk factors for coronary artery disease," Circulation Research, vol. 89, no. 1, pp. E1-E7, 2001.

[111] T. Asahara, T. Murohara, A. Sullivan et al., "Isolation of putative progenitor endothelial cells for angiogenesis," Science, vol. 275, no. 5302, pp. 964-967, 1997.

[112] S. Rafii and D. Lyden, "Therapeutic stem and progenitor cell transplantation for organ vascularization and regeneration," Nature Medicine, vol. 9, no. 6, pp. 702-712, 2003.

[113] E. Gunsilius, H. C. Duba, A. L. Petzer, C. M. Kähler, and G. A. Gastl, "Contribution of endothelial cells of hematopoietic origin to blood vessel formation," Circulation Research, vol. 88, no. 1, article E1, 2001.

[114] P. Sarto, E. Balducci, G. Balconi et al., "Effects of exercise training on endothelial progenitor cells in patients with chronic heart failure," Journal of Cardiac Failure, vol. 13, no. 9, pp. 701-708, 2007.

[115] C. de Ciuceis, C. Rossini, E. Porteri et al., "Circulating endothelial progenitor cells, microvascular density and fibrosis in obesity before and after bariatric surgery," Blood Press, vol. 22, no. 3, pp. 165-172, 2013.

[116] G. M. Rubanyi, "The role of endothelium in cardiovascular homeostasis and diseases," Journal of Cardiovascular Pharmacology, vol. 22, supplement 4, pp. S1-S14, 1993.

[117] P. M. Vanhoutte, "Regeneration of the endothelium in vascular injury," Cardiovascular Drugs and Therapy, vol. 24, no. 4, pp. 299-303, 2010.

[118] M. S.-K. Wong and P. M. Vanhoutte, "COX-mediated endothelium-dependent contractions: from the past to recent discoveries," Acta Pharmacologica Sinica, vol. 31, no. 9, pp. 1095$1102,2010$.

[119] K. Schrör, E. Bretschneider, K. Fischer et al., “Thrombin receptors in vascular smooth muscle cells-function and regulation by vasodilatory prostaglandins," Thrombosis and Haemostasis, vol. 103, no. 5, pp. 884-890, 2010. 
[120] D. Kerage, D. N. Brindley, and D. G. Hemmings, "Review: novel insights into the regulation of vascular tone by sphingosine 1phosphate," Placenta, vol. 35, pp. S86-S92, 2014.

[121] D. Feng, J. A. Nagy, K. Pyne, H. F. Dvorak, and A. M. Dvorak, "Neutrophils emigrate from venules by a transendothelial cell pathway in response to FMLP," Journal of Experimental Medicine, vol. 187, no. 6, pp. 903-915, 1998.

[122] C. V. Carman and T. A. Springer, "A transmigratory cup in leukocyte diapedesis both through individual vascular endothelial cells and between them," The Journal of Cell Biology, vol. 167, no. 2, pp. 377-388, 2004.

[123] E. C. Butcher, "Leukocyte-endothelial cell recognition: three (or more) steps to specificity and diversity," Cell, vol. 67, no. 6, pp. 1033-1036, 1991.

[124] M. Aurrand-Lions, C. Johnson-Leger, and B. A. Imhof, "The last molecular fortress in leukocyte trans-endothelial migration," Nature Immunology, vol. 3, no. 2, pp. 116-118, 2002.

[125] A. R. Pries and W. M. Kuebler, "Normal endothelium," Handbook of Experimental Pharmacology, part 1, no. 176, pp. 1-40, 2006.

[126] P. L. A. Giesen, U. Rauch, B. Bohrmann et al., "Blood-borne tissue factor: another view of thrombosis," Proceedings of the National Academy of Sciences of the United States of America, vol. 96, no. 5, pp. 2311-2315, 1999.

[127] W. C. Aird, "Vascular bed-specific hemostasis: role of endothelium in sepsis pathogenesis," Critical Care Medicine, vol. 29, supplement 7, pp. S28-S35, 2001.

[128] Z. Laszik, A. Mitro, F. B. Taylor Jr., G. Ferrell, and C. T. Esmon, "Human protein $\mathrm{C}$ receptor is present primarily on endothelium of large blood vessels: implications for the control of the protein C pathway," Circulation, vol. 96, no. 10, pp. 3633-3640, 1997.

[129] H. Ishii, H. H. Salem, and C. E. Bell, “Thrombomodulin, an endothelial anticoagulant protein, is absent from the human brain," Blood, vol. 67, no. 2, pp. 362-365, 1986.

[130] W. C. Aird, "Endothelial cell heterogeneity," Critical Care Medicine, vol. 31, supplement 4, pp. S221-S230, 2003.

[131] S. Verma and T. J. Anderson, "Fundamentals of endothelial function for the clinical cardiologist," Circulation, vol. 105, no. 5, pp. 546-549, 2002.

[132] R. Ross and J. A. Glomset, "Atherosclerosis and the arterial smooth muscle cell: proliferation of smooth muscle is a key event in the genesis of the lesions of atherosclerosis," Science, vol. 180 , no. 4093, pp. 1332-1339, 1973.

[133] W. C. Aird, "Spatial and temporal dynamics of the endothelium," Journal of Thrombosis and Haemostasis, vol. 3, no. 7, pp. 1392-1406, 2005.

[134] J. S. Pober and R. S. Cotran, "Cytokines and endothelial cell biology," Physiological Reviews, vol. 70, no. 2, pp. 427-451, 1990.

[135] W. Weninger, L. H. Ulfman, G. Cheng et al., "Specialized contributions by $\alpha(1,3)$-fucosyltransferase-IV and FucT-VII during leukocyte rolling in dermal microvessels," Immunity, vol. 12, no. 6, pp. 665-676, 2000.

[136] J. A. Suwaidi, S. Hamasaki, S. T. Higano, R. A. Nishimura, D. R. Holmes Jr., and A. Lerman, "Long-term follow-up of patients with mild coronary artery disease and endothelial dysfunction," Circulation, vol. 101, no. 9, pp. 948-954, 2000.

[137] V. Schächinger, M. B. Britten, and A. M. Zeiher, "Prognostic impact of coronary vasodilator dysfunction on adverse longterm outcome of coronary heart disease," Circulation, vol. 101, no. 16, pp. 1899-1906, 2000.
[138] H. Shimokawa, "Primary endothelial dysfunction: atherosclerosis," Journal of Molecular and Cellular Cardiology, vol. 31, no. 1, pp. 23-37, 1999.

[139] I. Ertenli, S. Kiraz, M. A. Öztürk et al., "Plasma fibronectin- and thrombospondin-adhesive molecules during acute attacks and attack-free periods of familial Mediterranean fever," Rheumatology International, vol. 20, no. 6, pp. 217-220, 2001.

[140] J. L. Mehta and D. Li, "Identification, regulation and function of a novel lectin-like oxidized low-density lipoprotein receptor," Journal of the American College of Cardiology, vol. 39, no. 9, pp. 1429-1435, 2002.

[141] H. Yoshida, N. Kondratenko, S. Green, D. Steinberg, and O. Quehenberger, "Identification of the lectin-like receptor for oxidized low-density lipoprotein in human macrophages and its potential role as a scavenger receptor," Biochemical Journal, vol. 334, part 1, pp. 9-13, 1998.

[142] T. Aoyama, M. Chen, H. Fujiwara, T. Masaki, and T. Sawamura, "LOX-1 mediates lysophosphatidylcholine-induced oxidized LDL uptake in smooth muscle cells," FEBS Letters, vol. 467, no. 2-3, pp. 217-220, 2000.

[143] S. Mitra, T. Goyal, and J. L. Mehta, "Oxidized LDL, LOX-1 and atherosclerosis," Cardiovascular Drugs and Therapy, vol. 25, no. 5, pp. 419-429, 2011.

[144] M. Honjo, K. Nakamura, K. Yamashiro et al., "Lectin-like oxidized LDL receptor-1 is a cell-adhesion molecule involved in endotoxin-induced inflammation," Proceedings of the National Academy of Sciences of the United States of America, vol. 100, no. 3, pp. 1274-1279, 2003.

[145] L. Cominacini, A. F. Pasini, U. Garbin et al., "The platelet-endothelium interaction mediated by lectin-like oxidized lowdensity lipoprotein receptor-1 reduces the intracellular concentration of nitric oxide in endothelial cells," Journal of the American College of Cardiology, vol. 41, no. 3, pp. 499-507, 2003.

[146] M. Chen, M. Kakutani, M. Minami et al., "Increased expression of lectinlike oxidized low density lipoprotein receptor-1 in initial atherosclerotic lesions of Watanabe heritable hyperlipidemic rabbits," Arteriosclerosis, Thrombosis, and Vascular Biology, vol. 20, no. 4, pp. 1107-1115, 2000.

[147] D. Y. Li, H. J. Chen, E. D. Staples et al., "Oxidized low-density lipoprotein receptor LOX-1 and apoptosis in human atherosclerotic lesions," Journal of Cardiovascular Pharmacology and Therapeutics, vol. 7, no. 3, pp. 147-153, 2002.

[148] M. Yan, J. L. Mehta, W. Zhang, and C. Hu, "LOX-1, oxidative stress and inflammation: a novel mechanism for diabetic cardiovascular complications," Cardiovascular Drugs and Therapy, vol. 25, no. 5, pp. 451-459, 2011.

[149] H. Chen, D. Li, T. Saldeen, and J. L. Mehta, “Transforming growth factor- $\beta 1$ modulates oxidatively modified LDL-induced expression of adhesion molecules: role of LOX-1," Circulation Research, vol. 89, no. 12, pp. 1155-1160, 2001.

[150] X. Wang, M. I. Phillips, and J. L. Mehta, "LOX-1 and angiotensin receptors, and their interplay," Cardiovascular Drugs and Therapy, vol. 25, no. 5, pp. 401-417, 2011.

[151] D. Li and J. L. Mehta, "Antisense to LOX-1 inhibits oxidized LDL-mediated upregulation of monocyte chemoattractant protein-1 and monocyte adhesion to human coronary artery endothelial cells," Circulation, vol. 101, no. 25, pp. 2889$2895,2000$.

[152] D. Li and J. L. Mehta, "Upregulation of endothelial receptor for oxidized LDL (LOX-1) by oxidized LDL and implications in apoptosis of coronary artery endothelial cells: evidence 
from use of antisense LOX-1 mRNA and chemical inhibitors," Arteriosclerosis, Thrombosis, and Vascular Biology, vol. 20, no. 4, pp. 1116-1122, 2000.

[153] M. Kakutani, T. Masaki, and T. Sawamura, "A platelet-endothelium interaction mediated by lectin-like oxidized lowdensity lipoprotein receptor-1," Proceedings of the National Academy of Sciences of the United States of America, vol. 97, no. 1, pp. 360-364, 2000.

[154] A. Rahman, A. L. True, K. N. Anwar, R. D. Ye, T. A. VoynoYasenetskaya, and A. B. Malik, "G $\alpha \mathrm{q}$ and $\mathrm{G} \beta \gamma$ regulate PAR-1 signaling of thrombin-induced NF- $\kappa \mathrm{B}$ activation and ICAM-1 transcription in endothelial cells," Circulation Research, vol. 91, no. 5, pp. 398-405, 2002.

[155] S. W. Klarenbach, A. Chipiuk, R. C. Nelson, M. D. Hollenberg, and A. G. Murray, "Differential actions of PAR2 and PAR1, in stimulating human endothelial cell exocytosis and permeability: the role of Rho-GTPases," Circulation Research, vol. 92, no. 3, pp. 272-278, 2003.

[156] L. Chi, Y. Li, L. Stehno-Bittel et al., "Interleukin-6 production by endothelial cells via stimulation of protease-activated receptors is amplified by endotoxin and tumor necrosis factor- $\alpha$," Journal of Interferon and Cytokine Research, vol. 21, no. 4, pp. 231-240, 2001.

[157] A. M. Zeiher, H. Drexler, H. Wollschlager, and H. Just, "Modulation of coronary vasomotor tone in humans. Progressive endothelial dysfunction with different early stages of coronary atherosclerosis," Circulation, vol. 83, no. 2, pp. 391-401, 1991.

[158] A. M. Zeiher, H. Drexler, B. Saurbier, and H. Just, "Endothelium-mediated coronary blood flow modulation in humans: effects of age, atherosclerosis, hypercholesterolemia, and hypertension," Journal of Clinical Investigation, vol. 92, no. 2, pp. 652662, 1993.

[159] M. A. Creager, J. P. Cooke, M. E. Mendelsohn et al., "Impaired vasodilation of forearm resistance vessels in hypercholesterolemic humans," Journal of Clinical Investigation, vol. 86, no. 1, pp. 228-234, 1990.

[160] R. J. Esper, R. Machado, J. Vilarino et al., "Endotheliumdependent responses in patients with hypercholesterolemic coronary artery disease under the effects of simvastatin and enalapril, either separately or combined," American Heart Journal, vol. 140, no. 4, pp. 684-689, 2000.

[161] R. A. Vogel, M. C. Corretti, and J. Gellman, "Cholesterol, cholesterol lowering, and endothelial function," Progress in Cardiovascular Diseases, vol. 41, no. 2, pp. 117-136, 1998.

[162] W.-H. Leung, C.-P. Lau, and C.-K. Wong, "Beneficial effect of cholesterol-lowering therapy on coronary endotheliumdependent relaxation in hypercholesterolaemic patients," The Lancet, vol. 341, no. 8859, pp. 1496-1500, 1993.

[163] B. Hornig, V. Maier, and H. Drexler, "Physical training improves endothelial function in patients with chronic heart failure," Circulation, vol. 93, no. 2, pp. 210-214, 1996.

[164] D. S. Celermajer, K. E. Sorensen, D. Georgakopoulos et al., "Cigarette smoking is associated with dose-related and potentially reversible impairment of endothelium-dependent dilation in healthy young adults," Circulation, vol. 88, no. 5, part 1, pp. 2149-2155, 1993.

[165] D. Urban, S. Ewen, C. Ukena, D. Linz, M. Böhm, and F. Mahfoud, "Treating resistant hypertension: role of renal denervation," Integrated Blood Pressure Control, vol. 6, pp. 119-128, 2013.

[166] J. Ketonen, J. Shi, E. Martonen, and E. Mervaala, "Periadventitial adipose tissue promotes endothelial dysfunction via oxidative stress in diet-induced obese C57BL/6 mice," Circulation Journal, vol. 74, no. 7, pp. 1479-1487, 2010.

[167] C. Lu, A. X. Zhao, Y.-J. Gao, and R. M. Lee, "Modulation of vein function by perivascular adipose tissue," European Journal of Pharmacology, vol. 657, no. 1-3, pp. 111-116, 2011.

[168] A. S. Greenstein, K. Khavandi, S. B. Withers et al., "Local inflammation and hypoxia abolish the protective anticontractile properties of perivascular fat in obese patients," Circulation, vol. 119, no. 12, pp. 1661-1670, 2009.

[169] T. Szasz, G. F. Bomfim, and R. C. Webb, "The influence of perivascular adipose tissue on vascular homeostasis," Journal of Vascular Health and Risk Management, vol. 9, pp. 105-116, 2013.

[170] F. M. Lynch, S. B. Withers, Z. Yao et al., "Perivascular adipose tissue-derived adiponectin activates $\mathrm{BK}(\mathrm{Ca})$ channels to induce anticontractile responses," American Journal of Physiology, vol. 304, no. 6, pp. H786-H795, 2013.

[171] Y.-J. Gao, Z.-H. Zeng, K. Teoh et al., "Perivascular adipose tissue modulates vascular function in the human internal thoracic artery," Journal of Thoracic and Cardiovascular Surgery, vol. 130, no. 4, pp. 1130-1136, 2005.

[172] R. M. Lee, C. Lu, L.-Y. Su, and Y.-J. Gao, "Endothelium-dependent relaxation factor released by perivascular adipose tissue," Journal of Hypertension, vol. 27, no. 4, pp. 782-790, 2009.

[173] B. Gálvez-Prieto, B. Somoza, M. Gil-Ortega et al., "Anticontractile effect of perivascular adipose tissue and leptin are reduced in hypertension," Frontiers in Pharmacology, vol. 3, article 103, 2012.

[174] Y. Higashi, S. Sukhanov, A. Anwar, S. Y. Shai, and P. Delafontaine, "Aging, atherosclerosis, and IGF-1," The Journals of Gerontology A, vol. 67, no. 6, pp. 626-639, 2012.

[175] M. A. Newaz and N. N. A. Nawal, "Effect of $\alpha$-tocopherol on lipid peroxidation and total antioxidant status in spontaneously hypertensive rats," American Journal of Hypertension, vol. 11, no. 12, pp. 1480-1485, 1998.

[176] R. Rezzani, E. Porteri, C. de Ciuceis et al., "Effects of melatonin and pycnogenol on small artery structure and function in spontaneously hypertensive rats," Hypertension, vol. 55, no. 6, pp. 1373-1380, 2010.

[177] L. F. Rodella, G. Favero, E. Foglio et al., "Vascular endothelial cells and dysfunctions: role of melatonin," Frontiers in Bioscience, vol. 5, pp. 119-129, 2013.

[178] C. M. Kolka and R. N. Bergman, “The endothelium in diabetes: its role in insulin access and diabetic complications," Reviews in Endocrine and Metabolic Disorders, vol. 14, no. 1, pp. 13-19, 2013.

[179] F. Giacco and M. Brownlee, "Oxidative stress and diabetic complications," Circulation Research, vol. 107, no. 9, pp. 10581070, 2010.

[180] R. T. de Jongh, E. H. Serné, R. G. Ijzerman, G. de Vries, and C. D. A. Stehouwer, "Impaired microvascular function in obesity: implications for obesity-associated microangiopathy, hypertension, and insulin resistance," Circulation, vol. 109, no. 21, pp. 2529-2535, 2004.

[181] A. E. Caballero, S. Arora, R. Saouaf et al., "Microvascular and macrovascular reactivity is reduced in subjects at risk for type 2 diabetes," Diabetes, vol. 48, no. 9, pp. 1856-1862, 1999.

[182] E. C. Eringa, C. D. A. Stehouwer, M. H. Roos, N. Westerhof, and P. Sipkema, "Selective resistance to vasoactive effects of insulin in muscle resistance arteries of obese Zucker (fa/fa) rats," American Journal of Physiology, vol. 293, no. 5, pp. E1134-E1139, 2007. 
[183] E. B. Okon, A. W. Y. Chung, P. Rauniyar et al., "Compromised arterial function in human type 2 diabetic patients," Diabetes, vol. 54, no. 8, pp. 2415-2423, 2005.

[184] R. I. Meijer, M. P. de Boer, M. R. Groen et al., "Insulin-induced microvascular recruitment in skin and muscle are related and both are associated with whole-body glucose uptake," Microcirculation, vol. 19, no. 6, pp. 494-500, 2012.

[185] E. Kostromina, N. Gustavsson, X. Wang et al., "Glucose intolerance and impaired insulin secretion in pancreas-specific signal transducer and activator of transcription-3 knockout mice are associated with microvascular alterations in the pancreas," Endocrinology, vol. 151, no. 5, pp. 2050-2059, 2010.

[186] J. S. Yudkin, C. D. A. Stehouwer, J. J. Emeis, and S. W. Coppack, "C-reactive protein in healthy subjects: associations with obesity, insulin resistance, and endothelial dysfunction: a potential role for cytokines originating from adipose tissue?" Arteriosclerosis, Thrombosis, and Vascular Biology, vol. 19, no. 4, pp. 972-978, 1999.

[187] R. Prakash, P. R. Somanath, A. B. El-Remessy et al., "Enhanced cerebral but not peripheral angiogenesis in the Goto-Kakizaki model of type 2 diabetes involves VEGF and peroxynitrite signaling," Diabetes, vol. 61, no. 6, pp. 1533-1542, 2012.

[188] S. C. Chang and W. C. V. Yang, "Hyperglycemia induces altered expressions of angiogenesis associated molecules in the trophoblast," Evidence-Based Complementary and Alternative Medicine, vol. 2013, Article ID 457971, 11 pages, 2013.

[189] K. H. Elçioğlu, L. Kabasakal, Ş. Çetinel, G. Conturk, S. F. Sezen, and G. Ayanoğlu-Dülger, "Changes in caveolin-1 expression and vasoreactivity in the aorta and corpus cavernosum of fructose and streptozotocin-induced diabetic rats," European Journal of Pharmacology, vol. 642, no. 1-3, pp. 113-120, 2010.

[190] E. N. Zeydanli, H. B. Kandilci, and B. Turan, "Doxycycline ameliorates vascular endothelial and contractile dysfunction in the thoracic aorta of diabetic rats," Cardiovascular Toxicology, vol. 11, no. 2, pp. 134-147, 2011.

[191] S. M. Shenouda, M. E. Widlansky, K. Chen et al., "Altered mitochondrial dynamics contributes to endothelial dysfunction in diabetes mellitus," Circulation, vol. 124, no. 4, pp. 444-453, 2011.

[192] A. B. Goldfine, J. A. Beckman, R. A. Betensky et al., "Family history of diabetes is a major determinant of endothelial function," Journal of the American College of Cardiology, vol. 47, no. 12, pp. 2456-2461, 2006.

[193] R. I. Meijer, E. H. Serne, Y. M. Smulders, V. W. M. van Hinsbergh, J. S. Yudkin, and E. C. Eringa, "Perivascular adipose tissue and its role in type 2 diabetes and cardiovascular disease," Current Diabetes Reports, vol. 11, no. 3, pp. 211-217, 2011.

[194] S. Hagita, M. Osaka, K. Shimokado, and M. Yoshida, "Adipose inflammation initiates recruitment of leukocytes to mouse femoral artery: role of adipo-vascular axis in chronic inflammation," PLoS ONE, vol. 6, no. 5, Article ID e19871, 2011.

[195] F. Kim, M. Pham, E. Maloney et al., "Vascular inflammation, insulin resistance, and reduced nitric oxide production precede the onset of peripheral insulin resistance," Arteriosclerosis, Thrombosis, and Vascular Biology, vol. 28, no. 11, pp. 1982-1988, 2008.

[196] E. C. Eringa, C. D. A. Stehouwer, K. Walburg et al., "Physiological concentrations of insulin induce endothelin-dependent vasoconstriction of skeletal muscle resistance arteries in the presence of tumor necrosis factor- $\alpha$ dependence on c-Jun N-terminal kinase," Arteriosclerosis, Thrombosis, and Vascular Biology, vol. 26, no. 2, pp. 274-280, 2006.
[197] W. Bakker, P. Sipkema, C. D. A. Stehouwer et al., "Protein kinase C $\theta$ activation induces insulin-mediated constriction of muscle resistance arteries," Diabetes, vol. 57, no. 3, pp. 706-713, 2008.

[198] R. I. Meijer, W. Bakker, C. L. Alta et al., "Perivascular adipose tissue control of insulin-induced vasoreactivity in muscle is impaired in db/db mice," Diabetes, vol. 62, no. 2, pp. 590-598, 2013.

[199] C. Rask-Madsen, H. Domínguez, N. Ihlemann, T. Hermann, L. Køber, and C. Torp-Pedersen, "Tumor necrosis factor- $\alpha$ inhibits insulin's stimulating effect on glucose uptake and endotheliumdependent vasodilation in humans," Circulation, vol. 108, no. 15, pp. 1815-1821, 2003.

[200] A. J. Houben, E. C. Eringa, A. M. Jonk, E. H. Serne, Y. M. Smulders, and C. D. Stehouwer, "Perivascular fat and the microcirculation: relevance to insulin resistance, diabetes, and cardiovascular disease," Current Cardiovascular Risk Reports , vol. 6, no. 1, pp. 80-90, 2012.

[201] T. K. Chatterjee, L. L. Stoll, G. M. Denning et al., "Proinflammatory phenotype of perivascular adipocytes: influence of high-fat feeding," Circulation Research, vol. 104, no. 4, pp. 541-549, 2009.

[202] E. Henrichot, C. E. Juge-Aubry, A. Pernin et al., "Production of chemokines by perivascular adipose tissue: a role in the pathogenesis of atherosclerosis?" Arteriosclerosis, Thrombosis, and Vascular Biology, vol. 25, no. 12, pp. 2594-2599, 2005.

[203] S. B. Withers, C. Agabiti-Rosei, D. M. Livingstone et al., "Macrophage activation is responsible for loss of anticontractile function in inflamed perivascular fat," Arteriosclerosis, Thrombosis, and Vascular Biology, vol. 31, no. 4, pp. 908-913, 2011.

[204] N. Hosogai, A. Fukuhara, K. Oshima et al., "Adipose tissue hypoxia in obesity and its impact on adipocytokine dysregulation," Diabetes, vol. 56, no. 4, pp. 901-911, 2007.

[205] J. Yin, Z. Gao, Q. He, D. Zhou, Z. Guo, and J. Ye, "Role of hypoxia in obesity-induced disorders of glucose and lipid metabolism in adipose tissue," American Journal of Physiology, vol. 296, no. 2, pp. E333-E342, 2009.

[206] N. K. Ghaisas, J. B. Foley, D. S. O’Briain, P. Crean, D. Kelleher, and M. Walsh, "Adhesion molecules in nonrheumatic aortic valve disease: endothelial expression, serum levels and effects of valve replacement," Journal of the American College of Cardiology, vol. 36, no. 7, pp. 2257-2262, 2000.

[207] A. M. Müller, C. Cronen, L. I. Kupferwasser, H. Oelert, K. M. Müller, and C. J. Kirkpatrick, "Expression of endothelial cell adhesion molecules on heart valves: up-regulation in degeneration as well as acute endocarditis," Journal of Pathology, vol. 191, no. 1, pp. 54-60, 2000.

[208] F. Chalajour, H. Treede, A. Ebrahimnejad, H. Lauke, H. Reichenspurner, and S. Ergun, "Angiogenic activation of valvular endothelial cells in aortic valve stenosis," Experimental Cell Research, vol. 298, no. 2, pp. 455-464, 2004.

[209] J. P. J. Halcox and A. A. Quyyumi, "Coronary vascular endothelial function and myocardial ischemia: why should we worry about endothelial dysfunction?" Coronary Artery Disease, vol. 12, no. 6, pp. 475-484, 2001.

[210] J. F. Argacha, D. Fontaine, D. Adamopoulos et al., "Acute effect of sidestream cigarette smoke extract on vascular endothelial function," Journal of Cardiovascular Pharmacology, vol. 52, no. 3, pp. 262-267, 2008.

[211] P. Balakumar, R. Sharma, and M. Singh, "Benfotiamine attenuates nicotine and uric acid-induced vascular endothelial dysfunction in the rat," Pharmacological Research, vol. 58, no. 5-6, pp. 356-363, 2008. 
[212] S. C. Campbell, R. J. Moffatt, and B. A. Stamford, "Smoking and smoking cessation-the relationship between cardiovascular disease and lipoprotein metabolism: a review," Atherosclerosis, vol. 201, no. 2, pp. 225-235, 2008.

[213] P. Balakumar and J. Kaur, "Is nicotine a key player or spectator in the induction and progression of cardiovascular disorders?" Pharmacological Research, vol. 60, no. 5, pp. 361-368, 2009.

[214] R. M. Pittilo, "Cigarette smoking and endothelial injury: a review," Advances in Experimental Medicine and Biology, vol. 273, pp. 61-78, 1990.

[215] D. Bernhard, A. Rossmann, and G. Wick, "Metals in cigarette smoke," IUBMB Life, vol. 57, no. 12, pp. 805-809, 2005.

[216] M. M. Rahman and I. Laher, "Structural and functional alteration of blood vessels caused by cigarette smoking: an overiew of molecular mechanisms," Current Vascular Pharmacology, vol. 5, no. 4, pp. 276-292, 2007.

[217] H.-L. Luo, W.-J. Zang, J. Lu, X.-J. Yu, Y.-X. Lin, and Y.-X. Cao, "The protective effect of captopril on nicotine-induced endothelial dysfunction in rat," Basic and Clinical Pharmacology and Toxicology, vol. 99, no. 3, pp. 237-245, 2006.

[218] C. R. W. Kuhlmann, J. R. F. C. Trümper, H. Tillmanns, C. A. Schaefer, and A. Erdogan, "Nicotine inhibits large conductance $\mathrm{Ca}^{2+}$-activated $\mathrm{K}^{+}$channels and the $\mathrm{NO}$-cGMP signaling pathway in cultured human endothelial cells," Scandinavian Cardiovascular Journal, vol. 39, no. 6, pp. 348-352, 2005.

[219] L. Erhardt, "Cigarette smoking: an undertreated risk factor for cardiovascular disease," Atherosclerosis, vol. 205, no. 1, pp. 2332, 2009.

[220] L. F. Rodella, C. Rossini, G. Favero, E. Foglio, C. Loreto, and R. Rezzani, "Nicotine-induced morphological changes in rat aorta: the protective role of melatonin," Cells Tissues Organs, vol. 195, no. 3, pp. 252-259, 2012.

[221] L. F. Rodella, G. Favero, C. Rossini, E. Foglio, R. J. Reiter, and R. Rezzani, "Endothelin-1 as a potential marker of melatonin's therapeutic effects in smoking-induced vasculopathy," Life Sciences, vol. 87, no. 17-18, pp. 558-564, 2010.

[222] X. L. Wang, M. Raveendran, and J. Wang, "Genetic influence on cigarette-induced cardiovascular disease," Progress in Cardiovascular Diseases, vol. 45, no. 5, pp. 361-382, 2003.

[223] M. D. Herrera, C. Mingorance, R. Rodríguez-Rodríguez, and M. A. de Sotomayor, "Endothelial dysfunction and aging: an update," Ageing Research Reviews, vol. 9, no. 2, pp. 142-152, 2010.

[224] A. U. Ferrari, A. Radaelli, and M. Centola, "Invited review: aging and the cardiovascular system," Journal of Applied Physiology, vol. 95, no. 6, pp. 2591-2597, 2003.

[225] R. L. Matz and R. Andriantsitohaina, "Age-related endothelial dysfunction: potential implications for pharmacotherapy," Drugs and Aging, vol. 20, no. 7, pp. 527-550, 2003.

[226] R. P. Brandes, I. Fleming, and R. Busse, "Endothelial aging," Cardiovascular Research, vol. 66, no. 2, pp. 286-294, 2005.

[227] A. A. Puca, A. Carrizzo, F. Villa et al., "Vascular ageing: the role of oxidative stress," The International Journal of Biochemistry \& Cell Biology, vol. 45, no. 3, pp. 556-559, 2013.

[228] S. M. L. Wallace, Y. Yasmin, C. M. McEniery et al., "Isolated systolic hypertension is characterized by increased aortic stiffness and endothelial dysfunction," Hypertension, vol. 50, no. 1, pp. 228-233, 2007.

[229] A. Csiszar, J. Toth, J. Peti-Peterdi, and Z. Ungvari, "The aging kidney: role of endothelial oxidative stress and inflammation," Acta Physiologica Hungarica, vol. 94, no. 1-2, pp. 107-115, 2007.
[230] J. M. Price, A. Hellermann, G. Hellermann, and E. T. Sutton, "Aging enhances vascular dysfunction induced by the Alzheimer's peptide $\beta$-amyloid," Neurological Research, vol. 26, no. 3, pp. 305-311, 2004.

[231] T. Kunieda, T. Minamino, K. Miura et al., "Reduced nitric oxide causes age-associated impairment of circadian rhythmicity," Circulation Research, vol. 102, no. 5, pp. 607-614, 2008.

[232] A. L. Burnett, "The role of nitric oxide in erectile dysfunction: implications for medical therapy," Journal of Clinical Hypertension, vol. 8, supplement 4, no. 12, pp. 53-62, 2006.

[233] M. Sanada, A. Taguchi, Y. Higashi et al., "Forearm endothelial function and bone mineral loss in postmenopausal women," Atherosclerosis, vol. 176, no. 2, pp. 387-392, 2004.

[234] H. R. Coleman, C.-C. Chan, F. L. Ferris III, and E. Y. Chew, "Agerelated macular degeneration," The Lancet, vol. 372, no. 9652, pp. 1835-1845, 2008.

[235] P. E. Gates, W. D. Strain, and A. C. Shore, "Human endothelial function and microvascular ageing," Experimental Physiology, vol. 94, no. 3, pp. 311-316, 2009.

[236] J. Lähteenvuo and A. Rosenzweig, "Effects of aging on angiogenesis," Circulation Research, vol. 110, no. 9, pp. 1252-1264, 2012.

[237] T. Finkel, "Oxidant signals and oxidative stress," Current Opinion in Cell Biology, vol. 15, no. 2, pp. 247-254, 2003.

[238] C. Vecchione and R. P. Brandes, "Withdrawal of 3-hydroxy-3methylglutaryl coenzyme A reductase inhibitors elicits oxidative stress and induces endothelial dysfunction in mice," Circulation Research, vol. 91, no. 2, pp. 173-179, 2002.

[239] Z. Ungvari, L. Bailey-Downs, D. Sosnowska et al., "Vascular oxidative stress in aging: a homeostatic failure due to dysregulation of NRF2-mediated antioxidant response," American Journal of Physiology, vol. 301, no. 2, pp. H363-H372, 2011.

[240] D.-F. Dai, P. S. Rabinovitch, and Z. Ungvari, "Mitochondria and cardiovascular aging," Circulation Research, vol. 110, no. 8, pp. 1109-1124, 2012.

[241] B. L. Tang, "Sirtl's systemic protective roles and its promise as a target in antiaging medicine," Translational Research, vol. 157, no. 5, pp. 276-284, 2011.

[242] S. Chung, H. Yao, S. Caito, J.-W. Hwang, G. Arunachalam, and I. Rahman, "Regulation of SIRT1 in cellular functions: role of polyphenols," Archives of Biochemistry and Biophysics, vol. 501, no. 1, pp. 79-90, 2010.

[243] A. M. Cuevas and A. M. Germain, "Diet and endothelial function," Biological Research, vol. 37, no. 2, pp. 225-230, 2004.

[244] S.-I. Yamagishi, T. Matsui, and K. Nakamura, "Atheroprotective properties of Pigment Epithelium-Derived Factor (PEDF) in cardiometabolic disorders," Current Pharmaceutical Design, vol. 15, no. 9, pp. 1027-1033, 2009.

[245] D. Ziegler, "Type 2 diabetes as an inflammatory cardiovascular disorder," Current Molecular Medicine, vol. 5, no. 3, pp. 309-322, 2005.

[246] J. Szostak and P. Laurant, "The forgotten face of regular physical exercise: a "natural" anti-atherogenic activity," Clinical Science, vol. 121, no. 3, pp. 91-106, 2011.

[247] M. D. Brown and D. L. Feairheller, "Are there race-dependent endothelial cell responses to exercise?” Exercise \& Sport Sciences Reviews, vol. 41, no. 1, pp. 44-54, 2013.

[248] K. E. Flynn, I. L. Piña, D. J. Whellan et al., "Effects of exercise training on health status in patients with chronic heart failure HF-ACTION randomized controlled trial," Journal of the American Medical Association, vol. 301, no. 14, pp. 1451-1459, 2009. 
[249] J. Downing and G. J. Balady, "The role of exercise training in heart failure," Journal of the American College of Cardiology, vol. 58, no. 6, pp. 561-569, 2011.

[250] J. Niebauer, "Effects of exercise training on inflammatory markers in patients with heart failure," Heart Failure Reviews, vol. 13, no. 1, pp. 39-49, 2008.

[251] K. C. Miranda, T. Huynh, Y. Tay et al., "A pattern-based method for the identification of MicroRNA binding sites and their corresponding heteroduplexes," Cell, vol. 126, no. 6, pp. 12031217, 2006.

[252] M. M. Fernandes-Silva, V. O. Carvalho, G. V. Guimarães, F. Bacal, and E. A. Bocchi, "Physical exercise and microRNAs: new frontiers in heart failure," Arquivos Brasileiros de Cardiologia, vol. 98, no. 5, pp. 459-466, 2012.

[253] R. A. Vogel, "The Mediterranean diet and endothelial function: why some dietary fats may be healthy," Cleveland Clinic Journal of Medicine, vol. 67, no. 4, article 232, pp. 235-236, 2000, Erratum in Cleveland Clinic Journal of Medicine, vol. 67, no. 7, article 467, 2000.

[254] N. Nicolaïew, N. Lemort, L. Adorni et al., "Comparison between extra virgin olive oil and oleic acid rich sunflower oil: effects on postprandial lipemia and LDL susceptibility to oxidation," Annals of Nutrition and Metabolism, vol. 42, no. 5, pp. 251-260, 1998.

[255] E. Lopez-Garcia, M. B. Schulze, J. B. Meigs et al., "Consumption of trans fatty acids is related to plasma biomarkers of inflammation and endothelial dysfunction," Journal of Nutrition, vol. 135, no. 3, pp. 562-566, 2005.

[256] J. M. Silva and C. Saldanha, "Diet, atherosclerosis and atherothrombotic events," Revista Portuguesa de Cardiologia, vol. 26, no. 3, pp. 277-294, 2007.

[257] F. B. Hu, J. E. Manson, and W. C. Willett, “Types of dietary fat and risk of coronary heart disease: a critical review," Journal of the American College of Nutrition, vol. 20, no. 1, pp. 5-19, 2001.

[258] D. Mozaffarian, "Trans fatty acids-effects on systemic inflammation and endothelial function," Atherosclerosis Supplements, vol. 7, no. 2, pp. 29-32, 2006.

[259] K. Esposito, R. Marfella, M. Ciotola et al., "Effect of a Mediterranean-style diet on endothelial dysfunction and markers of vascular inflammation in the metabolic syndrome: a randomized trial," Journal of the American Medical Association, vol. 292, no. 12, pp. 1440-1446, 2004.

[260] R. Estruch, M. A. Martínez-González, D. Corella et al., "Effects of a Mediterranean-style diet on cardiovascular risk factors a randomized trial," Annals of Internal Medicine, vol. 145, no. 1, pp. 1-11, 2006.

[261] M. Ryan, D. Mcinerney, D. Owens, P. Collins, A. Johnson, and G. H. Tomkin, "Diabetes and the Mediterranean diet: a beneficial effect of oleic acid on insulin sensitivity, adipocyte glucose transport and endothelium-dependent vasoreactivity," Monthly Journal of the Association of Physicians, vol. 93, no. 2, pp. 85-91, 2000.

[262] M. de Lorgeril, P. Salen, J.-L. Martin, I. Monjaud, J. Delaye, and N. Mamelle, "Mediterranean diet, traditional risk factors, and the rate of cardiovascular complications after myocardial infarction: final report of the Lyon Diet Heart study," Circulation, vol. 99, no. 6, pp. 779-785, 1999.

[263] W. J. E. Bemelmans, J. D. Lefrandt, E. J. M. Feskens et al., "Change in saturated fat intake is associated with progression of carotid and femoral intima-media thickness, and with levels of soluble intercellular adhesion molecule-1," Atherosclerosis, vol. 163, no. 1, pp. 113-120, 2002.
[264] A. Michalsen, N. Lehmann, C. Pithan et al., "Mediterranean diet has no effect on markers of inflammation and metabolic risk factors in patients with coronary artery disease," European Journal of Clinical Nutrition, vol. 60, no. 4, pp. 478-485, 2006.

[265] P. J. L. Ong, T. S. Dean, C. S. Hayward, P. L. D. Monica, T. A. B. Sanders, and P. Collins, "Effect of fat and carbohydrate consumption on endothelial function," The Lancet, vol. 354, no. 9196, article 2134, 1999.

[266] B. Khalfoun, G. Thibault, P. Bardos, and Y. Lebranchu, "Docosahexaenoic and eicosapentaenoic acids inhibit in vitro human lymphocyte-endothelial cell adhesion," Transplantation, vol. 62, no. 11, pp. 1649-1657, 1996.

[267] C. T. Kappagoda, D. A. Hyson, and E. A. Amsterdam, "Low-carbohydrate-high-protein diets: is there a place for them in clinical cardiology?" Journal of the American College of Cardiology, vol. 43, no. 5, pp. 725-730, 2004.

[268] E. C. Westman, W. S. Yancy Jr., M. K. Olsen, T. Dudley, and J. R. Guyton, "Effect of a low-carbohydrate, ketogenic diet program compared to a low-fat diet on fasting lipoprotein subclasses," International Journal of Cardiology, vol. 110, no. 2, pp. 212-216, 2006.

[269] W. E. Connor and S. L. Connor, "Should a low-fat, highcarbohydrate diet be recommended for everyone?" The New England Journal of Medicine, vol. 337, no. 8, pp. 562-563, 1997.

[270] M. B. Katan, S. M. Grundy, and W. C. Willett, "Beyond low-fat diets," The New England Journal of Medicine, vol. 337, no. 8, pp. 563-566, 1997.

[271] S. L. Weinberg, “The diet-heart hypothesis: a critique," Journal of the American College of Cardiology, vol. 43, no. 5, pp. 731-733, 2004.

[272] R. Landberg, N. Naidoo, and R. M. van Dam, "Diet and endothelial function: from individual components to dietary patterns," Current Opinion in Lipidology, vol. 23, no. 2, pp. 147-155, 2012.

[273] R. A. Vogel, M. C. Corretti, and G. D. Plotnick, "Effect of a single high-fat meal on endothelial function in healthy subjects," American Journal of Cardiology, vol. 79, no. 3, pp. 350-354, 1997.

[274] C. Marin, R. Ramirez, J. Delgado-Lista et al., "Mediterranean diet reduces endothelial damage and improves the regenerative capacity of endothelium," American Journal of Clinical Nutrition, vol. 93, no. 2, pp. 267-274, 2011.

[275] U. Scherrer, D. Randin, P. Vollenweider, L. Vollenweider, and P. Nicod, "Nitric oxide release accounts for insulin's vascular effects in humans," Journal of Clinical Investigation, vol. 94, no. 6, pp. 2511-2515, 1994.

[276] F. Pérez-Jiménez, P. Castro, J. López-Miranda et al., "Circulating levels of endothelial function are modulated by dietary monounsaturated fat," Atherosclerosis, vol. 145, no. 2, pp. 351358, 1999.

[277] F. Fuentes, J. López-Miranda, E. Sánchez et al., "Mediterranean and low-fat diets improve endothelial function in hypercholesterolemic men," Annals of Internal Medicine, vol. 134, no. 12, pp. 1115-1119, 2001.

[278] F. Leighton, S. Miranda-Rottmann, and I. Urquiaga, "A central role of eNOS in the protective effect of wine against metabolic syndrome," Cell Biochemistry and Function, vol. 24, no. 4, pp. 291-298, 2006.

[279] D. Grassi, G. Desideri, and C. Ferri, "Flavonoids: antioxidants against atherosclerosis," Nutrients, vol. 2, no. 8, pp. 889-902, 2010. 
[280] R. Rezzani, L. F. Rodella, S. Tengattini et al., "Protective role of polyphenols in cyclosporine A-induced nephrotoxicity during rat pregnancy," Journal of Histochemistry and Cytochemistry, vol. 54, no. 8, pp. 923-932, 2006.

[281] A. T. Dinkova-Kostova and P. Talalay, "Direct and indirect antioxidant properties of inducers of cytoprotective proteins," Molecular Nutrition and Food Research, vol. 52, supplement 1, pp. S128-S138, 2008.

[282] A. T. Dinkova-Kostova, J. Cheah, A. Samouilov et al., "Phenolic Michael reaction acceptors: combined direct and indirect antioxidant defenses against electrophiles and oxidants," Medicinal Chemistry, vol. 3, no. 3, pp. 261-268, 2007.

[283] M.-L. Hu, "Dietary polyphenols as antioxidants and anticancer agents: more questions than answers," Chang Gung Medical Journal, vol. 34, no. 5, pp. 449-460, 2011.

[284] B. Holst and G. Williamson, "Nutrients and phytochemicals: from bioavailability to bioefficacy beyond antioxidants," Current Opinion in Biotechnology, vol. 19, no. 2, pp. 73-82, 2008.

[285] L. Badimon, G. Vilahur, and T. Padro, "Nutraceuticals and atherosclerosis: human trials," Cardiovascular Therapeutics, vol. 28, no. 4, pp. 202-215, 2010.

[286] M. Kyaw, M. Yoshizumi, K. Tsuchiya, Y. Izawa, Y. Kanematsu, and T. Tamaki, "Atheroprotective effects of antioxidants through inhibition of mitogen-activated protein kinases," Acta Pharmacologica Sinica, vol. 25, no. 8, pp. 977-985, 2004.

[287] R. Rezzani, S. Tengattini, F. Bonomini et al., "Red wine polyphenols prevent cyclosporine-induced nephrotoxicity at the level of the intrinsic apoptotic pathway," Physiological Research, vol. 58, no. 4, pp. 511-519, 2009.

[288] C. Morand, C. Dubray, D. Milenkovic et al., "Hesperidin contributes to the vascular protective effects of orange juice: a randomized crossover study in healthy volunteers," American Journal of Clinical Nutrition, vol. 93, no. 1, pp. 73-80, 2011.

[289] S. J. Duffy, J. F. Keaney Jr., M. Holbrook et al., "Short- and longterm black tea consumption reverses endothelial dysfunction in patients with coronary artery disease," Circulation, vol. 104, no. 2, pp. 151-156, 2001.

[290] M.-I. Covas, “Olive oil and the cardiovascular system," Pharmacological Research, vol. 55, no. 3, pp. 175-186, 2007.

[291] J. S. Perona, R. Cabello-Moruno, and V. Ruiz-Gutierrez, "The role of virgin olive oil components in the modulation of endothelial function," Journal of Nutritional Biochemistry, vol. 17, no. 7, pp. 429-445, 2006.

[292] D. J. Hausenloy and D. M. Yellon, "Targeting residual cardiovascular risk: raising high-density lipoprotein cholesterol levels," Postgraduate Medical Journal, vol. 84, no. 997, pp. 590-598, 2008.

[293] M. A. Carluccio, M. Massaro, E. Scoditti, and R. de Caterina, "Vasculoprotective potential of olive oil components," Molecular Nutrition and Food Research, vol. 51, no. 10, pp. 1225-1234, 2007.

[294] A. Marquez-Martin, R. D. L. Puerta, A. Fernandez-Arche, V. Ruiz-Gutierrez, and P. Yaqoob, "Modulation of cytokine secretion by pentacyclic triterpenes from olive pomace oil in human mononuclear cells," Cytokine, vol. 36, no. 5-6, pp. 211217, 2006

[295] U. Simonsen, R. Rodriguez-Rodriguez, T. Dalsgaard, N. H. Buus, and E. Stankevicius, "Novel approaches to improving endothelium-dependent nitric oxide-mediated vasodilatation," Pharmacological Reports, vol. 61, no. 1, pp. 105-115, 2009.
[296] R. Masella, R. Varì, M. D’Archivio et al., "Extra virgin olive oil biophenols inhibit cell-mediated oxidation of LDL by increasing the mRNA transcription of glutathione-related enzymes," Journal of Nutrition, vol. 134, no. 4, pp. 785-791, 2004.

[297] R. Masella, R. di Benedetto, R. Vari, C. Filesi, and C. Giovannini, "Novel mechanisms of natural antioxidant compounds in biological systems: involvement of glutathione and glutathionerelated enzymes," Journal of Nutritional Biochemistry, vol. 16, no. 10, pp. 577-586, 2005.

[298] M. A. Carluccio, M. Massaro, C. Bonfrate et al., "Oleic acid inhibits endothelial activation: a direct vascular antiatherogenic mechanism of a nutritional component in the Mediterranean diet," Arteriosclerosis, Thrombosis, and Vascular Biology, vol. 19, no. 2, pp. 220-228, 1999.

[299] M. Massaro, M. A. Carluccio, A. Paolicchi, F. Bosetti, G. Solaini, and R. de Caterina, "Mechanisms for reduction of endothelial activation by oleate: inhibition of nuclear factor $\kappa \mathrm{B}$ through antioxidant effects," Prostaglandins Leukotrienes and Essential Fatty Acids, vol. 67, no. 2-3, pp. 175-181, 2002.

[300] P. Yaqoob, E. A. Newsholme, and P. C. Calder, "Inhibition of natural killer cell activity by dietary lipids," Immunology Letters, vol. 41, no. 2-3, pp. 241-247, 1994.

[301] P. Yaqoob, E. A. Newsholme, and P. C. Calder, “The effect of dietary lipid manipulation on rat lymphocyte subsets and proliferation," Immunology, vol. 82, no. 4, pp. 603-610, 1994.

[302] S. Tsimikas, A. Philis-Tsimikas, S. Alexopoulos, F. Sigari, C. Lee, and P. D. Reaven, "LDL isolated from Greek subjects on a typical diet or from American subjects on an oleate-supplemented diet induces less monocyte chemotaxis and adhesion when exposed to oxidative stress," Arteriosclerosis, Thrombosis, and Vascular Biology, vol. 19, no. 1, pp. 122-130, 1999.

[303] J. Ruano, J. Lopez-Miranda, F. Fuentes et al., "Phenolic content of virgin olive oil improves ischemic reactive hyperemia in hypercholesterolemic patients," Journal of the American College of Cardiology, vol. 46, no. 10, pp. 1864-1868, 2005.

[304] M. Fitó, R. de La Torre, and M.-I. Covas, "Olive oil and oxidative stress," Molecular Nutrition and Food Research, vol. 51, no. 10, pp. 1215-1224, 2007.

[305] G. Lippi, M. Franchini, E. J. Favaloro, and G. Targher, "Moderate red wine consumption and cardiovascular disease risk: beyond the French paradox," Seminars in Thrombosis and Hemostasis, vol. 36, no. 1, pp. 59-70, 2010.

[306] P. Gresele, C. Cerletti, G. Guglielmini, P. Pignatelli, G. de Gaetano, and F. Violi, "Effects of resveratrol and other wine polyphenols on vascular function: an update," Journal of Nutritional Biochemistry, vol. 22, no. 3, pp. 201-211, 2011.

[307] P. Bališ, A. Púzserová, P. Slezák, N. Sestáková, O. Pecháňová, and I. Bernátová, "Short-term administration of alibernet red wine extract failed to affect blood pressure and to improve endothelial function in young normotensive and spontaneously hypertensive rats," Physiological Research, vol. 62, no. 6, pp. 631641, 2013.

[308] J. Bornhoeft, D. Castaneda, T. Nemoseck, P. Wang, S. M. Henning, and M. Y. Hong, "The protective effects of green tea polyphenols: lipid profile, inflammation, and antioxidant capacity in rats fed an atherogenic diet and dextran sodium sulfate," Journal of Medicinal Food, vol. 15, no. 8, pp. 726-732, 2012.

[309] S. V. Nigdikar, N. R. Williams, B. A. Griffin, and A. N. Howard, "Consumption of red wine polyphenols reduces the susceptibility of low-density lipoproteins to oxidation in vivo," 
American Journal of Clinical Nutrition, vol. 68, no. 2, pp. 258265, 1998.

[310] A. Agouni, A.-H. Lagrue-Lak-Hal, H. A. Mostefai et al., "Red wine polyphenols prevent metabolic and cardiovascular alterations associated with obesity in Zucker fatty rats (Fa/Fa)," PLoS ONE, vol. 4, no. 5, Article ID e5557, 2009.

[311] G. Scola, D. Conte, P. W. D.-S. Spada et al., "Flavan-3-ol compounds from wine wastes with in vitro and in vivo antioxidant activity," Nutrients, vol. 2, no. 10, pp. 1048-1059, 2010.

[312] M. G. Lionetto, M. E. Giordano, A. Calisi, E. Erroi, F. de Nuccio, and T. Schettino, "Effect of the daily ingestion of a purified anthocyanin extract from grape skin on rat serum antioxidant capacity," Physiological Research, vol. 60, no. 4, pp. 637-645, 2011.

[313] T. Wallerath, G. Deckert, T. Ternes et al., "Resveratrol, a polyphenolic phytoalexin present in red wine, enhances expression and activity of endothelial nitric oxide synthase," Circulation, vol. 106, no. 13, pp. 1652-1658, 2002.

[314] K. Karatzi, E. Karatzis, C. Papamichael, J. Lekakis, and A. Zampelas, "Effects of red wine on endothelial function: postprandial studies vs clinical trials," Nutrition, Metabolism and Cardiovascular Diseases, vol. 19, no. 10, pp. 744-750, 2009.

[315] J. G. Zou, Z. R. Wang, Y. Z. Huang, K. J. Cao, and J. M. $\mathrm{Wu}$, "Effect of red wine and wine polyphenol resveratrol on endothelial function in hypercholesterolemic rabbits," International Journal of Molecular Medicine, vol. 11, no. 3, pp. 317-320, 2003.

[316] R. Jiménez, R. López-Sepúlveda, M. Kadmiri et al., "Polyphenols restore endothelial function in DOCA-salt hypertension: role of endothelin-1 and NADPH oxidase," Free Radical Biology and Medicine, vol. 43, no. 3, pp. 462-473, 2007.

[317] A. Cavallaro, T. Ainis, C. Bottari, and V. Fimiani, "Effect of resveratrol on some activities of isolated and in whole blood human neutrophils," Physiological Research, vol. 52, no. 5, pp. 555-562, 2003.

[318] S. K. Nicholson, G. A. Tucker, and J. M. Brameld, "Effects of dietary polyphenols on gene expression in human vascular endothelial cells," Proceedings of the Nutrition Society, vol. 67, no. 1, pp. 42-47, 2008.

[319] R. Corder, J. A. Douthwaite, D. M. Lees et al., "Endothelin-1 synthesis red wine," Nature, vol. 414, no. 6866, pp. 863-864, 2001.

[320] L. F. Rodella, L. Vanella, S. J. Peterson et al., "Heme oxygenasederived carbon monoxide restores vascular function in type 1 diabetes," Drug Metabolism Letters, vol. 2, no. 4, pp. 290-300, 2008.

[321] S. Hamed, J. Alshiek, A. Aharon, B. Brenner, and A. Roguin, "Red wine consumption improves in vitro migration of endothelial progenitor cells in young, healthy individuals," American Journal of Clinical Nutrition, vol. 92, no. 1, pp. 161-169, 2010.

[322] G. Chiva-Blanch, M. Urpi-Sarda, E. Ros et al., "Dealcoholized red wine decreases systolic and diastolic blood pressure and increases plasma nitric oxide: short communication," Circulation Research, vol. 111, no. 8, pp. 1065-1068, 2012.

[323] J. H. Stein, J. G. Keevil, D. A. Wiebe, S. Aeschlimann, and J. D. Folts, "Purple grape juice improves endothelial function and reduces the susceptibility of LDL cholesterol to oxidation in patients with coronary artery disease," Circulation, vol. 100, no. 10, pp. 1050-1055, 1999.

[324] A. C. M. Andrade, F. H. Y. Cesena, F. M. Consolim-Colombo et al., "Short-term red wine consumption promotes differential effects on plasma levels of high-density lipoprotein cholesterol, sympathetic activity, and endothelial function in hypercholesterolemic, hypertensive, and healthy subjects," Clinics, vol. 64, no. 5, pp. 435-442, 2009.

[325] P.-H. Huang, Y.-H. Chen, H.-Y. Tsai et al., "Intake of red wine increases the number and functional capacity of circulating endothelial progenitor cells by enhancing nitric oxide bioavailability," Arteriosclerosis, Thrombosis, and Vascular Biology, vol. 30, no. 4, pp. 869-877, 2010.

[326] C. D. Venkov, P. R. Myers, M. A. Tanner, M. Su, and D. E. Vaughan, "Ethanol increases endothelial nitric oxide production through modulation of nitric oxide synthase expression," Thrombosis and Haemostasis, vol. 81, no. 4, pp. 638-642, 1999.

[327] J. F. Leikert, T. R. Räthel, P. Wohlfart, V. Cheynier, A. M. Vollmar, and V. M. Dirsch, "Red wine polyphenols enhance endothelial nitric oxide synthase expression and subsequent nitric oxide release from endothelial cells," Circulation, vol. 106, no. 13, pp. 1614-1617, 2002.

[328] A. M. Cuevas, V. Guasch, O. Castillo et al., "A high-fat diet induces and red wine counteracts endothelial dysfunction in human volunteers," Lipids, vol. 35, no. 2, pp. 143-148, 2000.

[329] A. A. Quyyumi, "Prognostic value of endothelial function," American Journal of Cardiology, vol. 91, no. 12, pp. 19H-24H, 2003.

[330] T. Neunteufl, S. Heher, R. Katzenschlager et al., "Late prognostic value of flow-mediated dilation in the brachial artery of patients with chest pain," American Journal of Cardiology, vol. 86, no. 2, pp. 207-210, 2000.

[331] J. Lefèvre, S.-É. Michaud, P. Haddad et al., "Moderate consumption of red wine (cabernet sauvignon) improves ischemiainduced neovascularization in ApoE-deficient mice: effect on endothelial progenitor cells and nitric oxide," FASEB Journal, vol. 21, no. 14, pp. 3845-3852, 2007.

[332] P. A. Cahill and E. M. Redmond, "Alcohol and cardiovascular disease-modulation of vascular cell function," Nutrients, vol. 4, no. 4, pp. 297-318, 2012.

[333] A. P. Whelan, W. H. F. Sutherland, M. P. McCormick, D. J. Yeoman, S. A. de Jong, and M. J. A. Williams, "Effects of white and red wine on endothelial function in subjects with coronary artery disease," Internal Medicine Journal, vol. 34, no. 5, pp. 224228, 2004.

[334] S. Agewall, S. Wright, R. N. Doughty, G. A. Whalley, M. Duxbury, and N. Sharpe, "Does a glass of red wine improve endothelial function?" European Heart Journal, vol. 21, no. 1, pp. 74-78, 2000.

[335] M. Hashimoto, S. Kim, M. Eto et al., "Effect of acute intake of red wine on flow-mediated vasodilatation of the brachial artery," American Journal of Cardiology, vol. 88, no. 12, pp. 1457-1460, 2001.

[336] V. B. Schini-Kerth, C. Auger, J.-H. Kim, N. Etienne-Selloum, and T. Chataigneau, "Nutritional improvement of the endothelial control of vascular tone by polyphenols: role of $\mathrm{NO}$ and EDHF," Pflügers Archiv, vol. 459, no. 6, pp. 853-862, 2010.

[337] M. A. B. Rosales, K. C. Silva, J. B. L. de Faria, and J. M. L. de Faria, "Exogenous sod mimetic tempol ameliorates the early retinal changes reestablishing the redox status in diabetic hypertensive rats," Investigative Ophthalmology and Visual Science, vol. 51, no. 8, pp. 4327-4336, 2010.

[338] C. G. Schnackenberg and C. S. Wilcox, "The SOD mimetic tempol restores vasodilation in afferent arterioles of experimental diabetes," Kidney International, vol. 59, no. 5, pp. 1859-1864, 2001. 
[339] D. S. Weber and K. K. Griendling, "The Yin/Yang of superoxide dismutase mimetics: potential cardiovascular therapies?" British Journal of Pharmacology, vol. 139, no. 6, pp. 1059-1060, 2003.

[340] J. A. Rodríguez, A. Grau, E. Eguinoa et al., "Dietary supplementation with vitamins $C$ and $E$ prevents downregulation of endothelial NOS expression in hypercholesterolemia in vivo and in vitro," Atherosclerosis, vol. 165, no. 1, pp. 33-40, 2002.

[341] J.-H. Bae, E. Bassenge, K.-B. Kim et al., "Postprandial hypertriglyceridemia impairs endothelial function by enhanced oxidant stress," Atherosclerosis, vol. 155, no. 2, pp. 517-523, 2001.

[342] R. Maio, M. Perticone, A. Sciacqua et al., "Oxidative stress impairs endothelial function in nondipper hypertensive patients," Cardiovascular Therapeutics, vol. 30, no. 2, pp. 85-92, 2012.

[343] L. V. d'Uscio, S. Milstien, D. Richardson, L. Smith, and Z. S. Katusic, "Long-term vitamin $\mathrm{C}$ treatment increases vascular tetrahydrobiopterin levels and nitric oxide synthase activity," Circulation Research, vol. 92, no. 1, pp. 88-95, 2003.

[344] A. R. Crecelius, B. S. Kirby, W. F. Voyles, and F. A. Dinenno, "Nitric oxide, but not vasodilating prostaglandins, contributes to the improvement of exercise hyperemia via ascorbic acid in healthy older adults," American Journal of Physiology, vol. 299, no. 5, pp. H1633-H1641, 2010.

[345] J. D. Krier, E. L. Ritman, Z. Bajzer, J. C. Romero, A. Lerman, and L. O. Lerman, "Noninvasive measurement of concurrent singlekidney perfusion, glomerular filtration, and tubular function," American Journal of Physiology, vol. 281, no. 4, pp. F630-F638, 2001.

[346] J. Neužil, S. R. Thomas, and R. Stocker, "Requirement for, promotion, or inhibition by $\alpha$-tocopherol of radical- induced initiation of plasma lipoprotein lipid peroxidation," Free Radical Biology and Medicine, vol. 22, no. 1-2, pp. 57-71, 1996.

[347] J. F. Keaney Jr., J. M. Gaziano, A. Xu et al., "Low-dose $\alpha$-tocopherol improves and high-dose $\alpha$-tocopherol worsens endothelial vasodilator function in cholesterol-fed rabbits," Journal of Clinical Investigation, vol. 93, no. 2, pp. 844-851, 1994.

[348] D. Versari, E. Daghini, M. Rodriguez-Porcel et al., "Chronic antioxidant supplementation impairs coronary endothelial function and myocardial perfusion in normal pigs," Hypertension, vol. 47, no. 3, pp. 475-481, 2006.

[349] E. Daghini, X.-Y. Zhu, D. Versari et al., "Antioxidant vitamins induce angiogenesis in the normal pig kidney," American Journal of Physiology, vol. 293, no. 1, pp. F371-F381, 2007.

[350] S. R. J. Maxwell, "Coronary artery disease—free radical damage, antioxidant protection and the role of homocysteine," Basic Research in Cardiology, vol. 95, supplement 1, pp. I65-I71, 2000.

[351] R. J. Reiter, D.-X. Tan, S. D. Paredes, and L. Fuentes-Broto, "Beneficial effects of melatonin in cardiovascular disease," Annals of Medicine, vol. 42, no. 4, pp. 279-285, 2010.

[352] R. Hardeland, D.-X. Tan, and R. J. Reiter, "Kynuramines, metabolites of melatonin and other indoles: the resurrection of an almost forgotten class of biogenic amines," Journal of Pineal Research, vol. 47, no. 2, pp. 109-126, 2009.

[353] G. Paradies, G. Petrosillo, V. Paradies, R. J. Reiter, and F. M. Ruggiero, "Melatonin, cardiolipin and mitochondrial bioenergetics in health and disease," Journal of Pineal Research, vol. 48, no. 4, pp. 297-310, 2010.

[354] R. J. Reiter, D.-X. Tan, and A. Korkmaz, "The circadian melatonin rhythm and its modulation: possible impact on hypertension," Journal of Hypertension, vol. 27, supplement 6, pp. S17S20, 2009.
[355] A. Dominguez-Rodriguez, P. Abreu-Gonzalez, J. J. SanchezSanchez, J. C. Kaski, and R. J. Reiter, "Melatonin and circadian biology in human cardiovascular disease," Journal of Pineal Research, vol. 49, no. 1, pp. 14-22, 2010.

[356] L. Paulis, O. Pechanova, J. Zicha et al., "Melatonin improves the restoration of endothelium-derived constricting factor signalling and inner diameter in the rat femoral artery after cessation of L-NAME treatment," Journal of Hypertension, vol. 28, supplement 1, pp. S19-S24, 2010.

[357] F. Simko and L. Paulis, "Melatonin as a potential antihypertensive treatment," Journal of Pineal Research, vol. 42, no. 4, pp. 319322, 2007.

[358] C. F. Reyes-Toso, L. M. Linares, C. R. Ricci et al., "Melatonin restores endothelium-dependent relaxation in aortic rings of pancreatectomized rats," Journal of Pineal Research, vol. 39, no. 4, pp. 386-391, 2005.

[359] C. F. Reyes-Toso, D. Obaya-Naredo, C. R. Ricci et al., "Effect of melatonin on vascular responses in aortic rings of aging rats," Experimental Gerontology, vol. 42, no. 4, pp. 337-342, 2007.

[360] M. M. Anwar, A.-R. M. A. Meki, and H. H. Abu Rahma, "Inhibitory effects of melatonin on vascular reactivity: possible role of vasoactive mediators," Comparative Biochemistry and Physiology C, vol. 130, no. 3, pp. 357-367, 2001.

[361] M. L. Pita, M. Hoyos, I. Martin-Lacave, C. Osuna, J. M. Fernández-Santos, and J. M. Guerrero, "Long-term melatonin administration increases polyunsaturated fatty acid percentage in plasma lipids of hypercholesterolemic rats," Journal of Pineal Research, vol. 32, no. 3, pp. 179-186, 2002.

[362] S. Tengattini, R. J. Reiter, D.-X. Tan, M. P. Terron, L. F. Rodella, and R. Rezzani, "Cardiovascular diseases: protective effects of melatonin," Journal of Pineal Research, vol. 44, no. 1, pp. 16-25, 2008.

[363] H. Girouard and J. de Champlain, "Inhibitory effect of melatonin on $\alpha 1$-adrenergic-induced vasoconstriction in mesenteric beds of spontaneously hypertensive rats," American Journal of Hypertension, vol. 17, no. 4, pp. 339-346, 2004. 


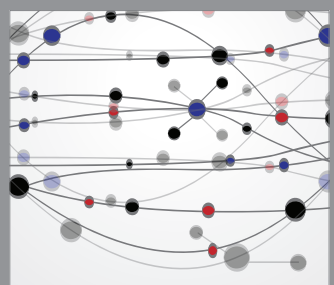

The Scientific World Journal
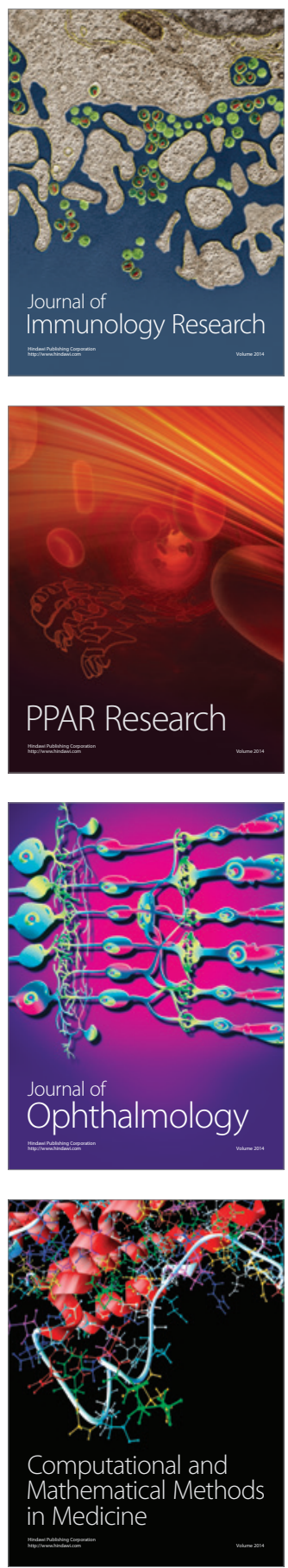

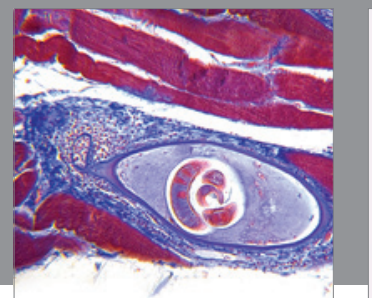

Gastroenterology

Research and Practice
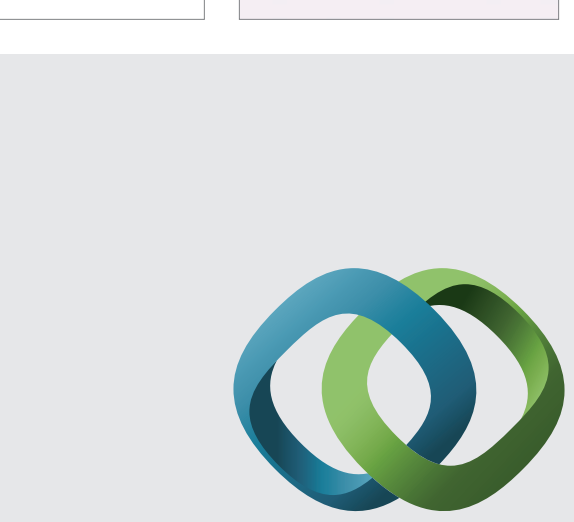

\section{Hindawi}

Submit your manuscripts at

http://www.hindawi.com
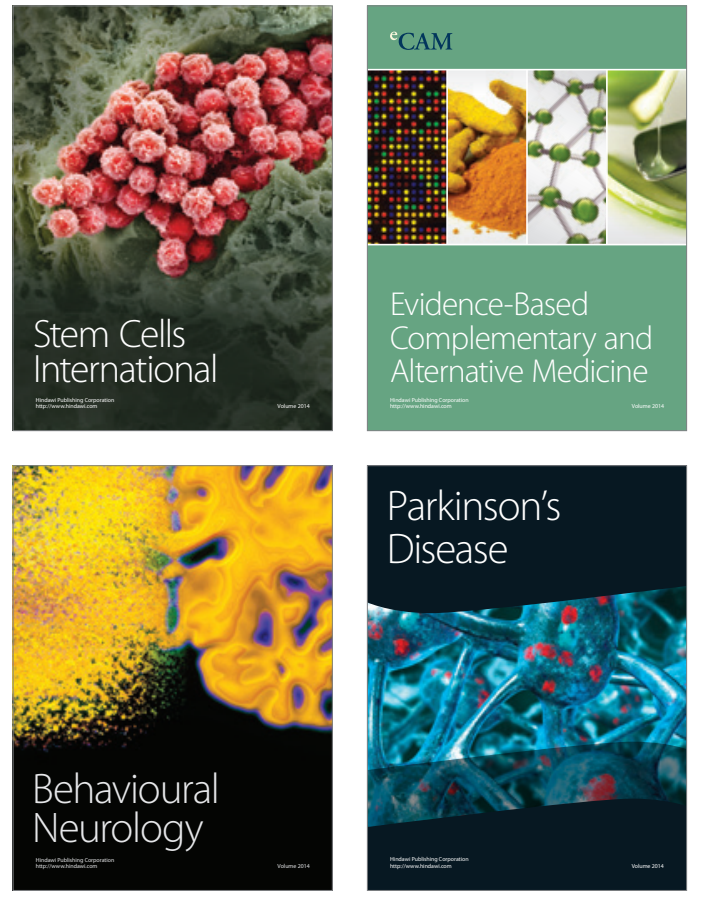
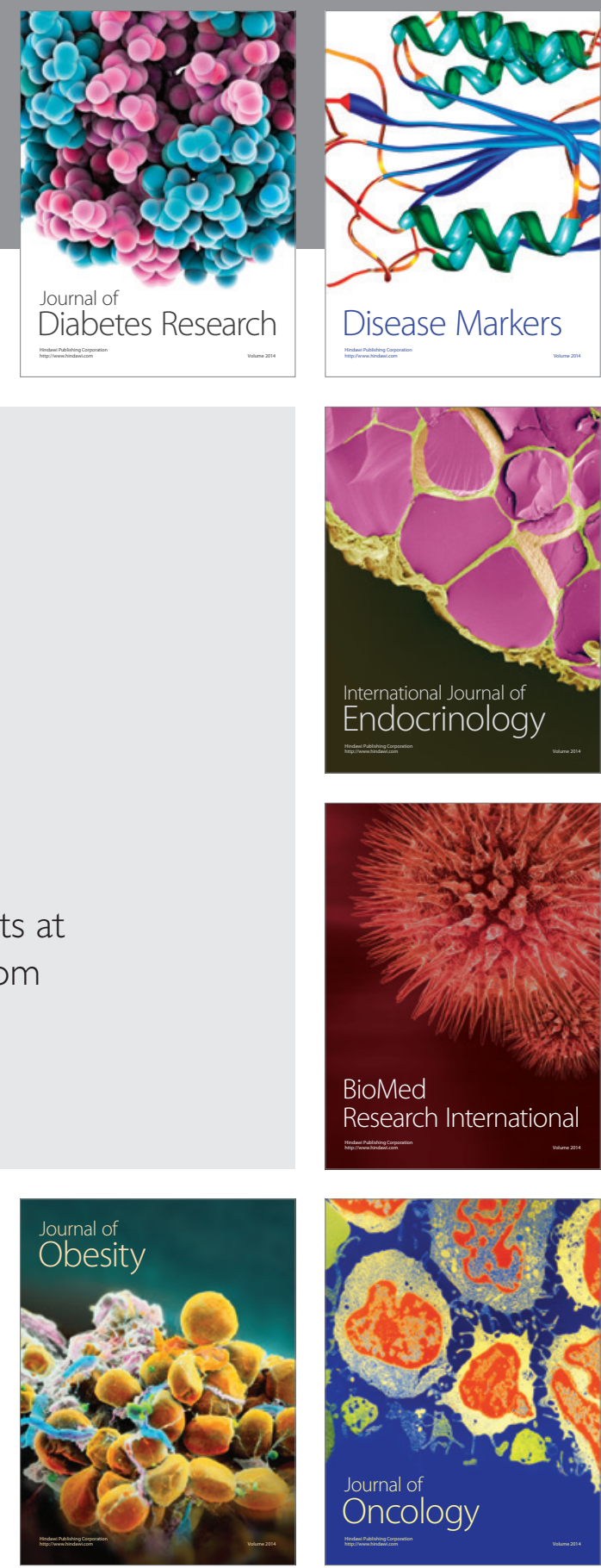

Disease Markers
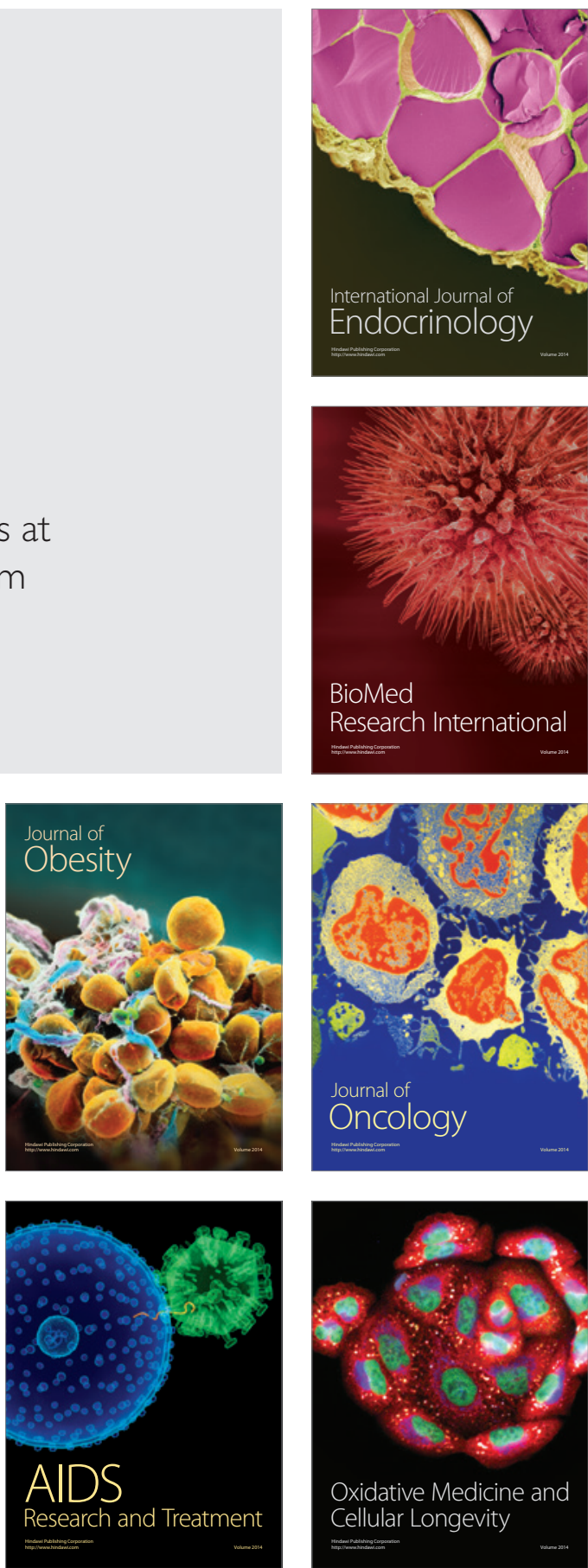